\title{
Factores de vulnerabilidad y reconstrucción posterremoto en tres localidades costeras chilenas: ¿generación de nuevas áreas de riesgo?
}

Vulnérabilités et reconstruction post-séisme dans trois villes côtières chiliennes: la création de nouvelles zones à risque?

Vulnerabilities and post-earthquake reconstruction in three Chilean coastal towns: generating new areas of risk?

\section{Carolina Martínez Reyes}

\section{OpenEdition}

Journals

Edición electrónica

URL: https://journals.openedition.org/bifea/5956

DOI: $10.4000 /$ bifea.5956

ISSN: 2076-5827

Editor

Institut Français d'Études Andines

Edición impresa

Fecha de publicación: 1 diciembre 2014

Paginación: 529-558

ISSN: 0303-7495

Referencia electrónica

Carolina Martínez Reyes, «Factores de vulnerabilidad y reconstrucción posterremoto en tres localidades costeras chilenas: ¿generación de nuevas áreas de riesgo?», Bulletin de l'Institut français d'études andines [En línea], 43 (3) | 2014, Publicado el 08 diciembre 2014, consultado el 07 diciembre 2022. URL: http://journals.openedition.org/bifea/5956 ; DOI: https://doi.org/10.4000/bifea.5956

\section{(c) $)(9)$}

Creative Commons - Atribución-NoComercial-SinDerivadas 4.0 Internacional - CC BY-NC-ND 4.0 https://creativecommons.org/licenses/by-nc-nd/4.0/ 


\title{
Factores de vulnerabilidad y reconstrucción posterremoto en tres localidades costeras chilenas: igeneración de nuevas áreas de riesgo?
}

\author{
Carolina Martínez Reyes*
}

\begin{abstract}
Resumen
Se analiza la vulnerabilidad asociada al tsunami del 27 de febrero de 2010 en tres localidades costeras de Chile centro sur, afectadas violentamente por este evento. El proceso de reconstrucción que se desarrolla en estas áreas lleva a plantear que se están produciendo nuevas áreas de riesgo favorecidas por este proceso. Se analizan los factores de la vulnerabilidad y su relación con las transformaciones socioterritoriales actuales vinculadas a lineamientos centralizados y que no han incorporado los elementos de creación de espacios a un nivel local, fundados en relaciones de dependencia con los recursos naturales como es el caso de las caletas de pescadores.
\end{abstract}

Palabras clave: riesgo natural, vulnerabilidad, planificación territorial, tsunami, resiliencia social

\section{Vulnérabilités et reconstruction post-séisme dans trois villes côtières chiliennes : la création de nouvelles zones à risque?}

\section{Résumé}

Cette article analyse la vulnérabilité associée au tsunami du 27 février 2010 dans trois villes côtières du centre-sud du Chili, violemment touchées par cet événement. Le processus de reconstruction en cours dans ces regions permet de voir qu'il existe de nouvelles zones à risque que ce processus favorise. Sont analysés les facteurs de vulnérabilité et leur relation avec les transformations socio-territoriales actuelles liées aux directives centralisées et n'ont pas intégré les éléments de l'espace de décision au

* Académica del Departamento de Geografía, Universidad de Concepción, Victoria s/n Barrio Universitario, Concepción, Chile. Casilla 169-C Fono: 41-2207197/ 2203233. E-mail: carolmartinez@udec.cl 
niveau local, en fonction des dépendances sur les ressources naturelles comme c'est le cas pour les villages de pêcheurs.

Mots-clés : risque naturel, vulnérabilité, planification, tsunami, résilience sociale

\title{
Vulnerabilities and post-earthquake reconstruction in three Chilean coastal towns: generating new areas of risk?
}

\begin{abstract}
In this article, we analyze the vulnerability associated with the tsunami of 27 February 2010 in three coastal towns in south-central Chile that were violently affected by this event. The Reconstruction that is currently under way in these areas leads us to propose that new risk areas are being by this process. Vulnerability factors and their relationship to the current socio-territorial transformations linked to centralized guidelines have not incorporated the elements of space at the local level, based on dependencies on natural resources such as case of fishing villages.
\end{abstract}

Keywords: natural risk, vulnerability, territorial planning, tsunami, social resilience

\section{INTRODUCCIÓN}

Los terremotos tsunamigénicos son unos de los fenómenos con mayor recurrencia histórica en la costa de Chile debido a su localización en la cuenca del Pacífico. Durante décadas han sido causantes de daños en la población y su infraestructura; sin embargo, dado el proceso de urbanización intensa que ha experimentado la costa chilena en los últimos años, este gran evento ocurrido el 27 de febrero de 2010 (27/F) generó una devastación sin precedentes, afectando especialmente pequeñas caletas de pescadores y puertos principales de la costa de Chile centro sur.

Los efectos del terremoto $(\mathrm{Mw}=8,8)$ del 27/F de 2010 y posterior tsunami fueron percibidos a lo largo de $600 \mathrm{~km}$ en la costa chilena, donde habita el 23\% de la población del país dividida en tres regiones administrativas. Unas 500 personas perdieron la vida, asimismo hubo destrucción de infraestructura costera y asentamientos humanos. El costo económico asociado se estimó en el 18\% del PIB nacional, debiendo destinarse recursos para reconstrucción principalmente de viviendas, infraestructura de salud, educación y obras públicas, en especial conectividad. Solo en infraestructura pública y privada el país habría perdido unos US\$ 20000 millones.

La ocupación de espacios expuestos a amenazas naturales es un problema común a nivel mundial pero se agrava particularmente en sociedades vulnerables. El ordenamiento territorial en su visión más moderna se concibe como un proceso en el cual la actividad humana se distribuye en forma sustentable en el territorio (Mc-Donald \& Simioni, 1999), identifica potencialidades y limitaciones (Vargas, 
2002) y, por lo tanto, constituye un medio para la corrección o el manejo de desequilibrios socioterritoriales (Gómez Orea, 1998). El uso sustentable de los recursos naturales y culturales, la localización de asentamientos en áreas seguras y el uso múltiple del suelo según aptitud y roles deberían ser orientados de acuerdo a lineamientos fundamentados en el conocimiento técnico-científico de los sistemas naturales y socioculturales, para su proyección en términos de adaptación ante escenarios de cambio, como por ejemplo cuando ocurren perturbaciones naturales de gran escala.

En Chile, los instrumentos de planificación territorial que plasman los criterios del ordenamiento territorial incorporan el tratamiento de los riesgos en las escalas comunales e intercomunales. Sin embargo, el énfasis está en ordenar los usos de suelo, las densidades habitacionales y la conectividad estructurante de las áreas exclusivamente urbanas, desatendiendo criterios de escalas de trabajo que requieren los estudios específicos de riesgos y las metodologías adecuadas para su análisis (Romero et al., 2010). En la mayoría de estos instrumentos, los estudios de riesgos naturales aparecen relegados a descripciones generales y no pueden ser considerados como criterios para proyectar adecuadamente los usos de suelo y el crecimiento urbano, lo cual explica en gran medida el grado de desastre que los eventos naturales de gran magnitud generan sobre asentamientos vulnerables. En este sentido, la vulnerabilidad representa una configuración de condiciones objetivas y subjetivas de existencia, históricamente determinadas y protagonizadas por sujetos colectivos concretos que originan o acentúan su predisposición ante ciertas amenazas y potencian la acción agresora de esta últimas (Campos, 1998 citado en Rojas \& Martínez, 2011). De este modo, las zonas con bajo valor de uso de suelo y expuestas a amenazas suelen ser áreas preferentes para emplazamiento de viviendas sociales que terminan configurando áreas segregadas, con escaso acceso a servicios públicos, falta de infraestructura comunitaria que facilite la cohesión social y ausencia de un manejo efectivo de los riesgos naturales. La vulnerabilidad, por lo tanto, se asocia a una falta de capacidad de la sociedad para responder a un suceso, en este caso un fenómeno natural peligroso (Anderson \& Woodrow, 1989 en Cardona, 2001; Wilches-Chaux, 1993).

De acuerdo con estudios de La Comisión Económica para América Latina (Cepal, 2007), de las 342 comunas que conforman el territorio nacional, el 39,5\% no tiene plan regulador ${ }^{1}$ y el 28,9\% no está actualizado. Según estas cifras, el 68,4\% del total de comunas no presenta instrumentos adecuados de planificación, ya sea porque no se han elaborado o porque estos son muy antiguos. Conforme a estos estudios, la principal debilidad es la calidad de estudios de riesgo y su incorporación a las zonificaciones que norman los usos de suelo. Esto último

1 El Plan Regulador Comunal es el principal instrumento de planificación territorial a nivel comunal en el país, orientado a promover el desarrollo armónico del territorio de acuerdo con las metas regionales de desarrollo económico-social. Es una figura legal emanada de la Ordenanza General de Urbanismo y Construcciones del Ministerio de Vivienda y Urbanismo. Norma el uso de suelo y fija límites urbanos, así como jerarquiza la red vial y proyecta la expansión urbana de la ciudad. 
sumado a una falta de coordinación y dispersión de funciones entre instituciones encargadas de la gestión del riesgo en el país, explicó en gran medida el nivel de destrucción generado por el terremoto y tsunami del 27/F de 2010.

Así como el terremoto de 1960 generó un avance sustantivo en materia de edificación y a la vez posibilitó la coordinación entre países ribereños de la cuenca del Pacífico en torno a un sistema internacional de alarma de tsunami (PTWC), el terremoto de 2010 posibilitó la inclusión de estudios fundados de riesgo en los nuevos planes reguladores a nivel comunal, modificó la norma antisísmica para las nuevas construcciones y creó directrices para una nueva institucionalidad encargada de la gestión del riesgo de desastres siguiendo el Marco de Acción de $\mathrm{Hyogo}^{2}$. A pesar de esto y a escala local, la reconstrucción de las ciudades afectadas se realiza a partir de Planes Maestros de Reconstrucción (PRBC-18)3, los cuales han materializado cambios en el territorio difíciles de dimensionar debido a la complejidad que implica medir procesos sociales en un territorio cambiante. Sin embargo, la nueva configuración urbana y rural que se presenta, se piensa, está generando nuevas áreas con un potencial de riesgo mayor debido al énfasis que se ha puesto en la reconstrucción física del territorio emanada de una visión de gobernanza centralizada o nacional y no regional/local.

El propósito de esta contribución, por lo tanto, es analizar los factores de vulnerabilidad ante un tsunami y cómo se asocia el proceso de reconstrucción posterremoto con las nuevas áreas de riesgo, proceso que se desarrolla actualmente en gran parte de Chile centro sur. Para ello se han considerado tres localidades costeras de la Región del Biobío $\left(37^{\circ} \mathrm{S}\right)$, dos de ellas rurales, caracterizadas por vinculaciones profundas con el medio natural, asociadas a la extracción de productos del mar, condiciones socioeconómicas vulnerables y que fueron violentamente afectadas por el tsunami del 27/F. Estas localidades fueron elegidas por el nivel de destrucción que tuvo el tsunami y porque actualmente experimentan una notable transformación en torno a una infraestructura costera y habitacional en los mismos lugares arrasados por el tsunami y en aquellas que aún son rurales, transitan rápidamente a situaciones de periurbanización.

2 El Marco de Acción de Hyogo (MAH) fue el resultado operativo de la Segunda Conferencia Mundial de las Naciones Unidas sobre la Reducción de Desastres celebrada en Kobe (Hyogo), Japón, en 2005. A través de la Estrategia Internacional para la Reducción de Desastres (UNISDR) se pretende que para el año 2015 todos los países miembros logren aumentar la resiliencia de los grupos humanos y sus asentamientos. Esto con el fin de reducir el riesgo de desastres a partir de objetivos estratégicos y áreas prioritarias de acción, entre ellas la planificación para el desarrollo sostenible y el fortalecimiento de la institucionalidad en la gestión del riesgo.

3 Los Planes de Reconstrucción del Borde Costero (PRBC-18) fueron diseñados desde la Intendencia Regional para planificar la reconstrucción en 18 comunas costeras de la Región del Biobío que fueron severamente afectadas por el terremoto y tsunami del 27/F de 2010. Tienen un componente de diagnóstico y otro de participación ciudadana; sin embargo, el escaso tiempo en el cual fueron diseñados hizo que se presentara el mismo diseño estructural para todas las localidades, dificultando la restauración de barrios y elementos de identidad local. 


\section{EL CONTEXTO GEOGRÁFICO DE LAS LOCALIDADES COSTERAS}

La costa de la Región del Biobío forma parte de un sistema conjugado de bahías abiertas al norte. En esta costa se incluye el tercer conglomerado urbano del país (Concepción Metropolitano), el cual ha sido históricamente desarrollado en torno al eje costero. Es así que de las 54 comunas que forman la región, 14 corresponden a comunas costeras, las que agrupan al 51\% de la población regional.

Las localidades de Tubul, Coliumo y Dichato, corresponden a asentamientos costeros. La primera se ubica en el Golfo de Arauco y las dos últimas dentro de la bahía de Coliumo (fig. 1). Caleta Tubul se localiza en la ribera del río Tubul $\left(37^{\circ} \mathrm{S}\right)$ el cual forma parte de un sistema interconectado de cuencas costeras (Tubul y Raqui) cuya superficie conjunta es de $274 \mathrm{~km}^{2}$, las cuales dan origen a uno de los humedales costeros más importantes de la región por su diversidad biológica. La caleta posee una superficie no superior a $3 \mathrm{~km}^{2}$ y vincula una población rural de unos 2000 habitantes cuya principal actividad era hasta antes del tsunami del 27/F, la pesca artesanal y la recolección de algas. Dichato y Coliumo $\left(36^{\circ} \mathrm{S}\right)$ comparten el mismo sistema de bahía, donde la primera se localiza en la zona norte. La alta ubicuidad de la bahía, la presencia de planicies de playa con desarrollo de humedales y la presencia de los esteros Dichato y Coliumo hacen de esta bahía una zona vulnerable ante la amenaza de tsunamis, tal como ha ocurrido con eventos históricos. Dichato hasta antes del tsunami del 27/F poseía una población de 3488 habitantes (INE, 2003) dedicada a actividades económicas ligadas a la pesca, al comercio y principalmente al turismo. Coliumo por su parte, es un antiguo asentamiento rural de unos 931 habitantes (INE, 2003), vinculado a la pesca artesanal. Esta actividad se desarrolla en tres áreas geográficas de la bahía siendo la principal Vegas de Coliumo.

Las tres áreas se caracterizan por el perfil socioeconómico vulnerable de su población, dado que presentan una fuerte condición de pobreza que se agravó luego de ocurrido el tsunami: gran parte de la población perdió su fuente de ingreso, sus viviendas y su medio de trabajo.

\section{APROXIMACIÓN METODOLÓGICA AL ESTUDIO DE VULNERABILIDADES SOCIOTERRITORIALES}

Dado que los efectos provocados por el tsunami de 2010 en las localidades costeras de Chile centro sur generaron una instancia de trabajo interdisciplinario en el estudio de vulnerabilidades socioterritoriales ante este tipo de fenómenos naturales, la experiencia recogida en los aspectos metodológicos se expone en Martínez et al. (2012) y Martínez (2014), destacando las siguientes actividades aplicadas a las localidades analizadas: 


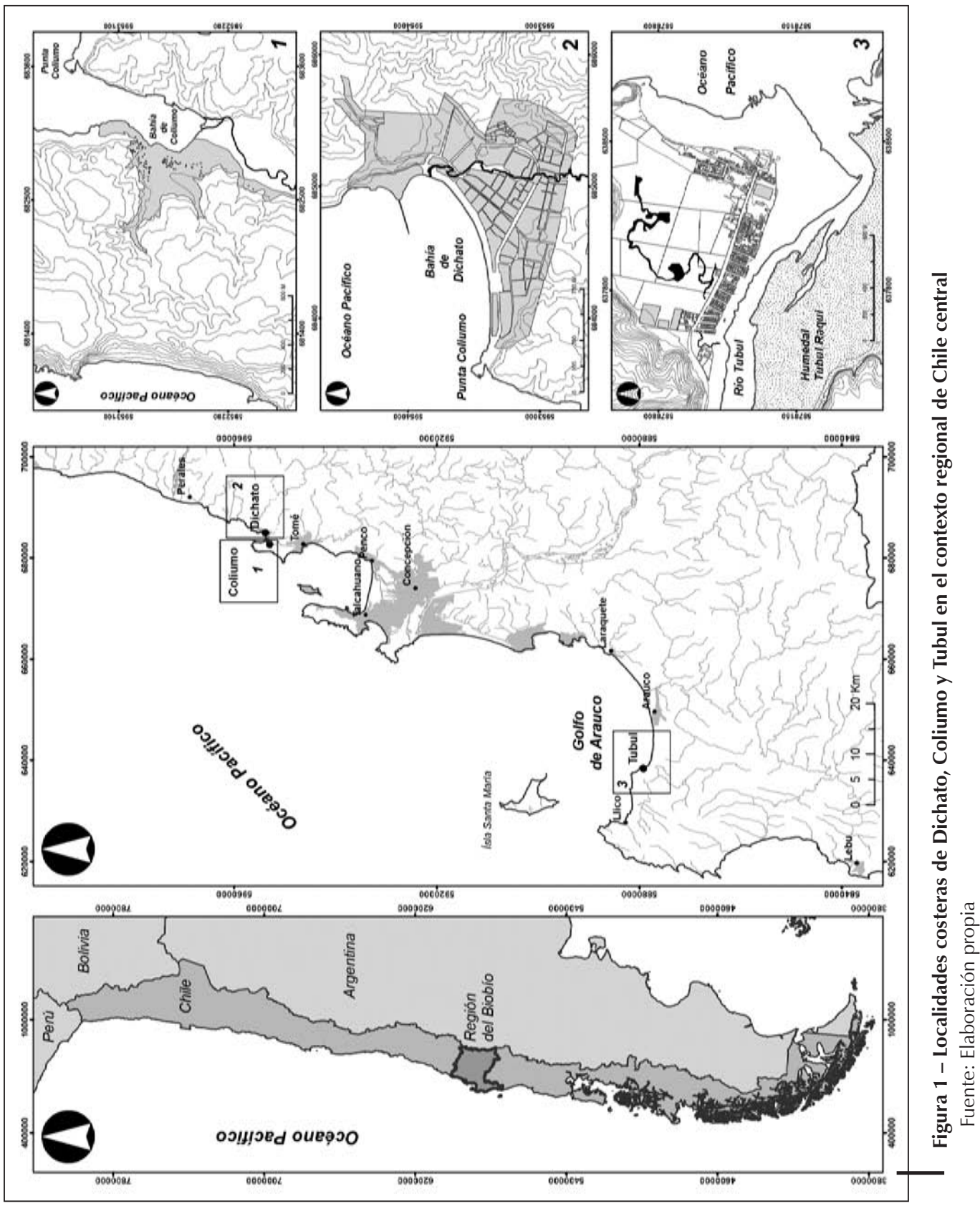




\section{1. Determinación de escenarios extremos de tsunami que definen áreas de inundación y altura de ola máxima (la condición más desfavorable)}

Estos fueron determinados mediante análisis de recurrencia histórica utilizando información de catálogos sísmicos y crónicas históricas disponibles en Lomnitz (1970; 1971), Kausel (1986), Urrutia \& Lanza (1993), Díaz (1992), Monge (1993), Lorca \& Recabarren (1994), Lagos (2000), Quezada et al. (2010) y Palacios (2012). Esta actividad permitió delimitar el área de influencia del tsunami en función del peor escenario esperado y sus efectos sobre la población.

\section{2. Análisis de vulnerabilidad}

Se consideró la vulnerabilidad en función de sus diferentes dimensiones de acuerdo con los criterios de Wilches-Chaux (1993) con el propósito de adoptar variables de análisis adecuadas a la realidad sociocultural de cada localidad. La mayoría de autores coinciden en que la vulnerabilidad se asocia a elementos frágiles de una persona o grupo humano que generan una predisposición a sufrir daño (Cardona, 2001; Lavell, 2001). Según Wilches-Chaux (1993), estos elementos o condiciones de fragilidad pueden ser agrupados en diferentes dimensiones: física, social, organizacional, educativa y otras. Los factores que la originan dependen del grado de exposición al evento, la fragilidad social (marginalidad y segregación social) y la falta de resiliencia o incapacidad de respuesta para absorber el impacto (Blakie, 1994 citado en Rojas \& Martínez, 2011). En función de esto, fue necesario conocer previamente la realidad socioeconómica y cultural de los asentamientos para seleccionar las variables que pudieran reflejar mejor la vulnerabilidad global.

La unidad de análisis adoptada fue la manzana censal para las localidades urbanas (Dichato) o unidades definidas con herramientas de Sistemas de Información Geográfica para localidades rurales (Coliumo y Tubul). Las dimensiones de la vulnerabilidad consideradas fueron física, socioeconómica y educativa, de acuerdo con criterios de valoración. En Coliumo, fue posible medir la vulnerabilidad ideológico-cultural a través de las variables identidad territorial y apego.

Dado que la única localidad urbana es Dichato, fue posible utilizar datos de manzana censal del último censo (INE, 2003) y validar el análisis de vulnerabilidad con los efectos del tsunami de 2010. Las otras dos áreas (Coliumo y Tubul) no poseen información censal por lo cual los datos fueron extraídos a partir de encuestas posterremoto con muestreo estratificado para poblaciones finitas y con significancia estadística (Ireland, 2012; Altamirano, 2012; Martínez et al., 2012).

A cada variable relacionada con una dimensión de la vulnerabilidad se le asoció un nivel de vulnerabilidad en tres clases: alta (A), media (M) y baja (B), según la ponderación indicada en los cuadros 1-3 donde los resultados fueron espacializados en el Sistema de Información Geográfico (SIG ArcGis). 
Cuadro 1 - Variables consideradas para la vulnerabilidad física

\begin{tabular}{|c|c|c|c|}
\hline Variable & Característica & Ponderación & Fuente \\
\hline Tipo de vivienda & $\begin{array}{l}\text { Casa o departamento } \\
\text { Conventillo o mediagua } \\
\text { Rancho o choza }\end{array}$ & $\begin{array}{l}1 \\
2 \\
3\end{array}$ & $\begin{array}{l}\text { Ministerio de Vivienda } \\
\text { y Urbanismo } \\
(\text { MINVU, 2004) }\end{array}$ \\
\hline $\begin{array}{l}\text { Materialidad de } \\
\text { la vivienda }\end{array}$ & $\begin{array}{l}\text { Hormigón, ladrillo } \\
\text { Madera, paneles estructurados } \\
\text { Internit, adobe o barro }\end{array}$ & $\begin{array}{l}1 \\
2 \\
3\end{array}$ & $\begin{array}{l}\text { Ministerio de Vivienda } \\
\text { y Urbanismo } \\
\text { (MINVU, 2004) }\end{array}$ \\
\hline $\begin{array}{l}\text { Calidad y } \\
\text { resistencia de la } \\
\text { vivienda }\end{array}$ & $\begin{array}{l}\text { Muy resistente } \\
\text { Medianamente resistente } \\
\text { Poco resistente }\end{array}$ & $\begin{array}{l}1 \\
2 \\
3\end{array}$ & $\begin{array}{l}\text { Ministerio de Vivienda } \\
\text { y Urbanismo } \\
(\text { MINVU, 2004) }\end{array}$ \\
\hline $\begin{array}{l}\text { Cercanía a la } \\
\text { costa }\end{array}$ & $\begin{array}{l}\text { No inundable } \\
\text { (sobre cota segura de } 25 \text { m) } \\
\text { Intermedia } \\
\text { (entre cota de inundación de } \\
\text { evento extremo y los } 25 \text { m) } \\
\text { Inundable } \\
\text { (dentro de cota de inundación } \\
\text { histórica) }\end{array}$ & 2 & $\begin{array}{l}\text { Modificado de Flores } \\
\text { (2011) }\end{array}$ \\
\hline
\end{tabular}

Cuadro 2 - Variables consideradas para la vulnerabilidad socioeconómica

\begin{tabular}{|c|c|c|c|}
\hline Variable & Característica & Ponderación & Fuente \\
\hline Nivel de ingreso & $\begin{array}{l}\text { Quintil } 1 \text { y } 2(<\text { US\$ 380) } \\
\text { Quintil } 3 \text { y } 4 \text { (US\$ 381-840) } \\
\text { Quintil } 5 \text { (> US\$ 840) }\end{array}$ & $\begin{array}{l}1 \\
2 \\
3\end{array}$ & $\begin{array}{l}\text { MIDEPLAN (2007) y } \\
\text { encuestas }\end{array}$ \\
\hline $\begin{array}{l}\text { Actividad } \\
\text { económica }\end{array}$ & $\begin{array}{l}\text { Terciario } \\
\text { (dentro de la localidad) } \\
\text { Terciario y secundario } \\
\text { (fuera de localidad) } \\
\text { Primario (actividades } \\
\text { vinculadas a la pesca) }\end{array}$ & 1 & Encuesta \\
\hline $\begin{array}{l}\text { Viviendas con } \\
\text { hacinamiento }\end{array}$ & $\begin{array}{l}\text { De } 1 \text { a } 2,5 \text { personas por } \\
\text { habitación } \\
\text { De } 2,5 \text { a } 3,5 \text { personas por } \\
\text { habitación } \\
>3,5 \text { personas por } \\
\text { habitación }\end{array}$ & $\begin{array}{l}2 \\
3\end{array}$ & $\begin{array}{l}\text { Ministerio de Vivienda } \\
\text { y Urbanismo } \\
\text { (MINVU, 2004) } \\
\text { y encuesta }\end{array}$ \\
\hline
\end{tabular}


Factores de vulnerabilidad y reconstrucción posterremoto en tres localidades costeras chilenas

Cuadro 3 - Variables consideradas para la vulnerabilidad educativa

\begin{tabular}{|c|c|c|c|}
\hline Variable & Característica & Ponderación & Fuente \\
\hline \multirow{3}{*}{$\begin{array}{l}\text { Nivel de } \\
\text { conocimiento } \\
\text { sobre tsunamis }\end{array}$} & Tiene conocimiento formal & 1 & \multirow{3}{*}{ Encuesta } \\
\hline & Asigna la causa a fuerzas divinas & 2 & \\
\hline & No tiene conocimiento & 3 & \\
\hline \multirow{3}{*}{ Nivel de reacción } & $\begin{array}{l}\text { Evacuó el área oportunamente y se } \\
\text { dirigió a zona segura }\end{array}$ & 1 & \multirow{3}{*}{ Encuesta } \\
\hline & $\begin{array}{l}\text { No sabía cómo reaccionar, sin } \\
\text { embargo evacuó a zona segura }\end{array}$ & 2 & \\
\hline & No evacuó, se quedó en su vivienda & 3 & \\
\hline \multirow{3}{*}{$\begin{array}{l}\text { Viviendas con } \\
\text { hacinamiento }\end{array}$} & De 1 a 2,5 personas por habitación & 1 & \multirow{3}{*}{ Encuesta } \\
\hline & $\begin{array}{l}\text { De } 2,5 \text { a } 3,5 \text { personas por } \\
\text { habitación }\end{array}$ & 2 & \\
\hline & > 3,5 personas por habitación & 3 & \\
\hline
\end{tabular}

Para la síntesis final de la vulnerabilidad, se realizó un álgebra de mapas ponderando las cartografías síntesis de cada dimensión de la vulnerabilidad de acuerdo con los criterios de Venegas (2012).

\section{EL PEOR ESCENARIO Y LOS FACTORES QUE EXPLICAN LA VULNERABILIDAD EN LAS LOCALIDADES COSTERAS}

\section{1. La recurrencia histórica y los escenarios extremos en las localidades analizadas}

Los terremotos de 1730 y 1835, de acuerdo con los registros históricos (cuadro 4), son los que han generado mayor grado de desastre en las costas de la Región del Biobío; sin embargo, el de 1730 se ha destacado por algunas investigaciones en desarrollo, como uno de los gigantes de la historia (Cisternas et al., 2011).

De este modo, para Caleta Tubul se determinó que el evento extremo constituye el tsunami de 1835 el cual alcanzó alturas de ola de 10 m (Martínez et al., 2012), mientras que para Dichato el evento extremo fue el tsunami del 27/F de 2010 (fig. 2) y para Coliumo correspondió al tsunami de 2010 (Ireland, 2012). Se debe destacar también que a un año de producirse el terremoto de 2010, la costa de la región volvió a ser afectada por un tsunami pero esta vez de campo lejano. El 11 de marzo de 2011 se produjo el terremoto de Honshu, en Japón, el cual se propagó en toda la cuenca del Pacífico, registrando en Vegas de Coliumo una superficie de propagación mayor de inundación que para el evento de 2010 (fig. 3). El tsunami de Japón se registró en todas las localidades afectadas por el tsunami de 2010, con alturas de flujo bajas y no como olas violentas; sin embargo, en la mayoría de los casos el área de inundación fue la misma que en 2010. 
Cuadro 4 - Sismos tsunamigénicos históricos en la costa de Chile centro sur

\begin{tabular}{|c|c|c|c|c|}
\hline Fecha & Localización & Magnitud & $\begin{array}{l}\text { Run up } \\
\text { (m) }\end{array}$ & Efectos \\
\hline $\begin{array}{l}1562 \\
(28 \text { de octubre) }\end{array}$ & $38^{\circ} \mathrm{S}-73^{\circ} \mathrm{W}$ & 8,0 & 16 & $\begin{array}{l}\text { El tsunami afectó la costa a lo largo de } \\
1200 \mathrm{~km}\end{array}$ \\
\hline $\begin{array}{l}1570 \\
\text { (08 de febrero) }\end{array}$ & $36,5^{\circ} \mathrm{S}-74^{\circ} \mathrm{W}$ & $\begin{aligned} & 8,5 \\
L & =240 \mathrm{~km}\end{aligned}$ & 4 & $\begin{array}{l}2000 \text { muertos debido al tsunami. La } \\
\text { ciudad de Concepción se ubicaba } \\
\text { entonces en el lugar que hoy ocupa Penco } \\
\text { (bahía de Talcahuano) }\end{array}$ \\
\hline $\begin{array}{l}1575 \\
\text { (16 de } \\
\text { diciembre) }\end{array}$ & $\begin{array}{l}38,5^{\circ} \mathrm{S}- \\
74,5^{\circ} \mathrm{W}\end{array}$ & 8,5 & 4 & $\begin{array}{l}\text { Ciudades más afectadas fueron Valdivia, } \\
\text { Osorno y Villarrica }\end{array}$ \\
\hline $\begin{array}{l}1657 \\
\text { (15 de marzo) }\end{array}$ & $37^{\circ} \mathrm{S}-72,8^{\circ} \mathrm{W}$ & $\begin{array}{c}8,0 \\
L=150 \mathrm{~km}\end{array}$ & 4 & $\begin{array}{l}\text { Hubo unos } 40 \text { muertos y reiterados trenes } \\
\text { de olas. Los efectos fueron comparables a } \\
\text { los tsunamis de } 1570 \text { y } 1835\end{array}$ \\
\hline $\begin{array}{l}1730 \\
\text { (08 de julio) }\end{array}$ & $\begin{array}{l}32,5^{\circ} \mathrm{S}- \\
71,5^{\circ} \mathrm{W}\end{array}$ & $\begin{array}{c}8,7 \\
\mathrm{~L}=900 \mathrm{~km} ?\end{array}$ & 16 & $\begin{array}{l}\text { A pesar de que el terremoto no se registró } \\
\text { frente a las costas de la región, el tsunami } \\
\text { generado es uno de los más devastadores } \\
\text { de la historia en la región y en la costa del } \\
\text { Pacífico }\end{array}$ \\
\hline $\begin{array}{l}1751 \\
\text { (25 de mayo) }\end{array}$ & $36,5^{\circ} \mathrm{S}-74^{\circ} \mathrm{W}$ & $\begin{aligned} & 8,5 \\
L & =330 \mathrm{~km}\end{aligned}$ & 3,5 & $\begin{array}{l}\text { Tsunami destructivo, arrasó la costa } \\
\text { de la región, alcanzó el archipiélago } \\
\text { Juan Fernández y habría alcanzado } \\
\text { hasta las costas de Japón. La ciudad de } \\
\text { Concepción, localizada en Penco, tuvo } \\
\text { que ser refundada en su actual sitio }\end{array}$ \\
\hline $\begin{array}{l}1835 \\
\text { (20 de febrero) }\end{array}$ & $36,8^{\circ} \mathrm{S}-73^{\circ} \mathrm{W}$ & $\begin{aligned} & 8,0 \\
L & =280 \mathrm{~km}\end{aligned}$ & 15 & $\begin{array}{l}\text { La costa de la región fue asolada por } \\
\text { el terremoto y tsunami posterior. En } \\
\text { Concepción se registraron } 60 \text { muertos y } \\
500 \text { heridos }\end{array}$ \\
\hline $\begin{array}{l}1960 \\
\text { (20 de mayo) }\end{array}$ & $\begin{array}{l}38,5^{\circ} \mathrm{S}- \\
74,5^{\circ} \mathrm{W}\end{array}$ & $\begin{aligned} & 9,5 \\
L & =900 \mathrm{~km}\end{aligned}$ & 15 & $\begin{array}{l}\text { Hubo } 2000 \text { muertos, terremoto y tsunami } \\
\text { devastador en la costa de Chile y Hawaii, } \\
\text { Oceanía y Japón. Considerado el evento } \\
\text { más catastrófico de la historia humana. El } \\
\text { tsunami fue registrado en toda la cuenca } \\
\text { del Pacífico }\end{array}$ \\
\hline $\begin{array}{l}2010 \\
(27 \text { de febrero) }\end{array}$ & $\begin{array}{l}36,2^{\circ} \mathrm{S}- \\
72,9^{\circ} \mathrm{W}\end{array}$ & $\begin{aligned} & 8,8 \\
\mathrm{~L} & =500 \mathrm{~km}\end{aligned}$ & 10 & $\begin{array}{l}\text { Hubo } 524 \text { muertos. Los efectos se } \\
\text { registraron a lo largo de } 500 \text { km de costa, } \\
\text { alcanzó el archipiélago Juan Fernández y } \\
\text { las costas del Océano Pacífico }\end{array}$ \\
\hline
\end{tabular}

Fuente: Belmonte-Pool (1997); Martínez et al. (2011) 
Factores de vulnerabilidad y reconstrucción posterremoto en tres localidades costeras chilenas

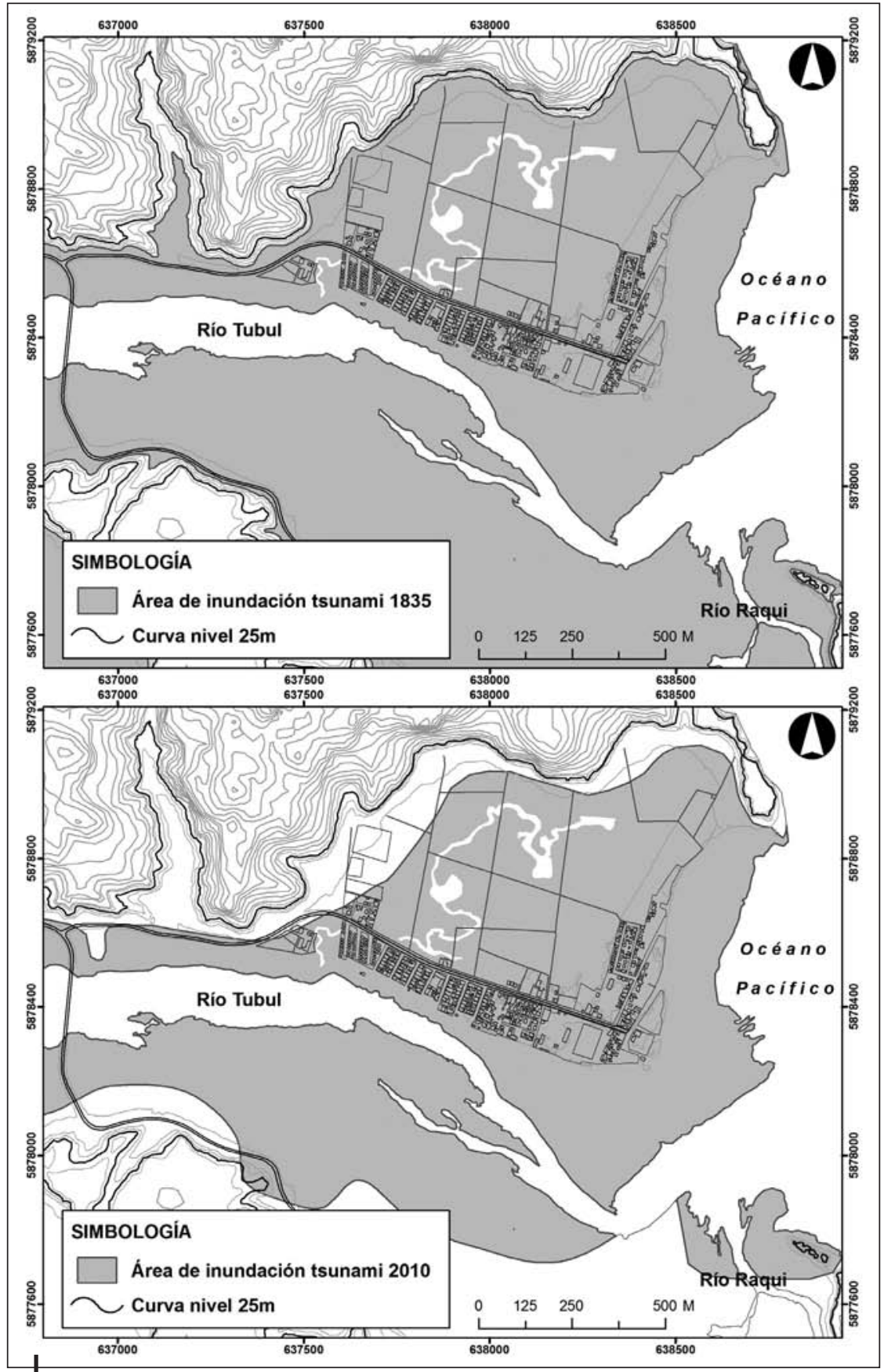

Figura 2 - Área de inundación por el tsunami del 27/F de 2010, localidad de Tubul Fuente: Modificado de Martínez et al. (2012) 


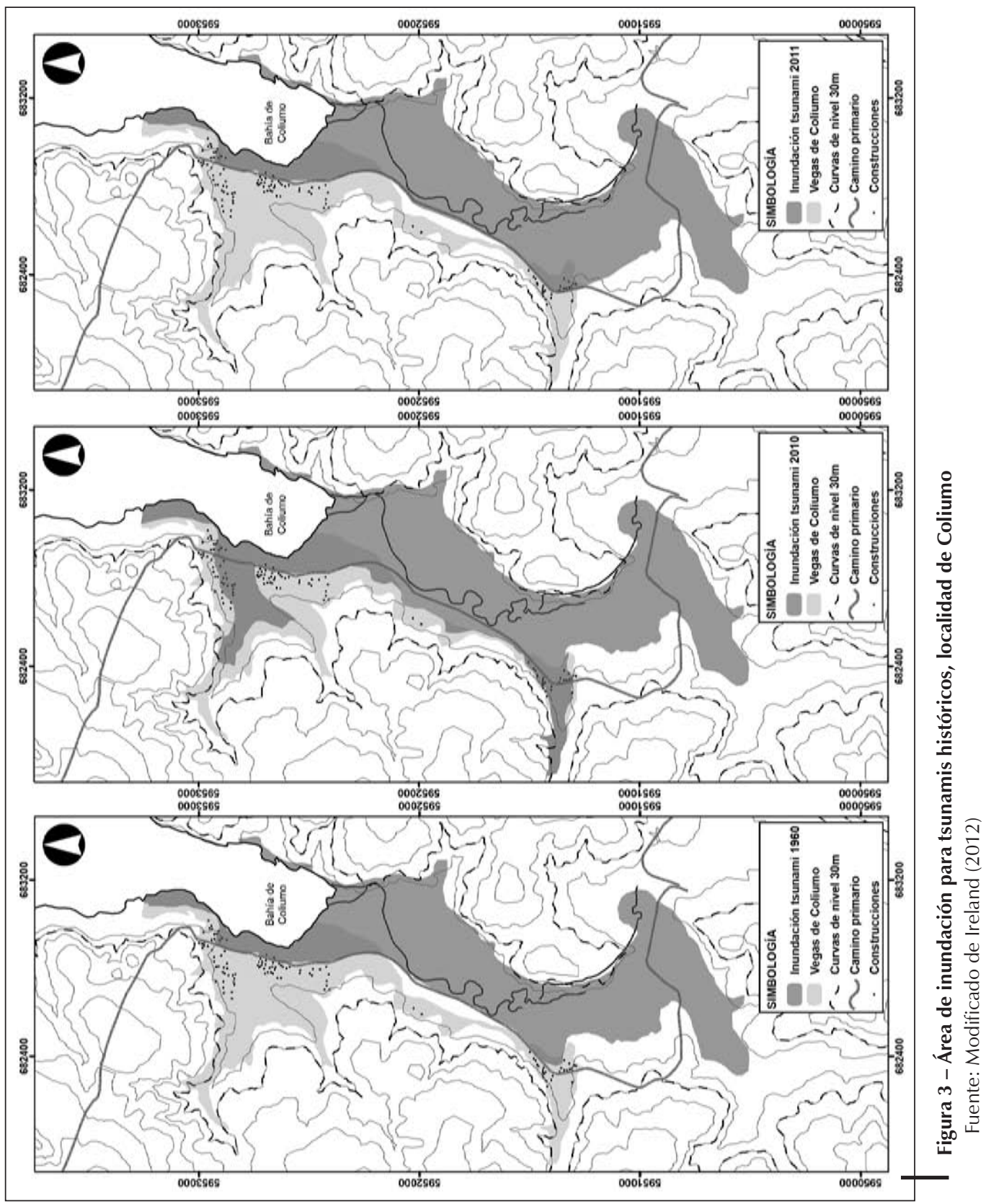


En el caso del tsunami de 27/F de 2010 en Tubul, la inundación se propagó hasta $3 \mathrm{~km}$ al interior afectando gran parte de la planicie de playa entre los ríos Tubul y Raqui. El tsunami afectó con mayor violencia el asentamiento costero en aquellos sectores próximos a la playa, donde el run up de la ola alcanzó los $5 \mathrm{~m}$. Las alturas de flujo en el resto de la localidad llegaron a 1 m (Martínez et al., 2012).

En Dichato, el tsunami actuó con gran impacto (fig. 4), arrasando totalmente el asentamiento con olas que alcanzaron un run up entre 7 y $9 \mathrm{~m}$. En Vegas de Coliumo el run up de la ola alcanzó los $7 \mathrm{~m}$ y la superficie inundada fue de $1,5 \mathrm{~km}^{2}$ con una máxima distancia de propagación de $3 \mathrm{~km}$; es decir, el tsunami bordeó la paleobahía (Martínez et al., 2011). Las viviendas más cercanas a la orilla fueron arrasadas y arrastradas hacia el interior.

En las tres localidades el tsunami utilizó los cursos de agua locales para incrementar la superficie de propagación, así las condiciones naturales de las bahías asociadas (alta ubicuidad y orientación de las bahías, baja altura y escasa pendiente de las planicies de playa, presencia de esteros) facilitaron los daños ocasionados.

\section{2. Los factores de la vulnerabilidad social ante el evento}

\section{2. 1. Dichato}

Antes del tsunami del 27/F de 2010, la localidad de Dichato era reconocida por sus actividades socioeconómicas ligadas a la pesca artesanal y al turismo, consolidando un núcleo urbano diferenciado de las localidades costeras aledañas, como Perales y Coliumo. Según el censo de 2002 (INE, 2002) la población llegaba a 4384 habitantes, donde el área urbana concentraba a 3488 habitantes.

El estudio de vulnerabilidad total realizado comparando los escenarios pre y posevento a nivel de manzana censal (Venegas, 2012), estableció que en el caso de la vulnerabilidad física para condiciones preevento, el 51\% de las manzanas censales registró alta vulnerabilidad en función del tipo de vivienda, su materialidad y precariedad, involucrando al $47 \%$ de la superficie del área bajo inundación (cota segura $25 \mathrm{msnm}$ ) y al $57 \%$ de la población total.

Considerando el perfil socioeconómico de la población, el 73\% de las viviendas registró vulnerabilidad media, involucrando el $61 \%$ delárea y al $67 \%$ de la población. Lo anterior se explicó debido a la localización de la población en usos de suelo residenciales donde habita más del $75 \%$ de esta, además posee ingresos bajos pero vive sin hacinamiento. Al respecto, el $44 \%$ de los habitantes percibe ingresos inferiores a \$ 118000 chilenos (unos US\$ 100). Para la vulnerabilidad educativa se determinó que el bajo nivel de escolaridad influyó en la vulnerabilidad total dado que el $42 \%$ de los habitantes solo tiene educación básica o no ha completado este nivel y el 55\% tiene educación secundaria. Es importante destacar que el 58\% de la población atribuyó a un terremoto las causas de un tsunami, pero el 42\% lo atribuyó a causas divinas, incluso al calentamiento global y al apocalipsis. De acuerdo con esto, el 54\% de la población presentó vulnerabilidad educativa alta involucrando al 74\% del área. 


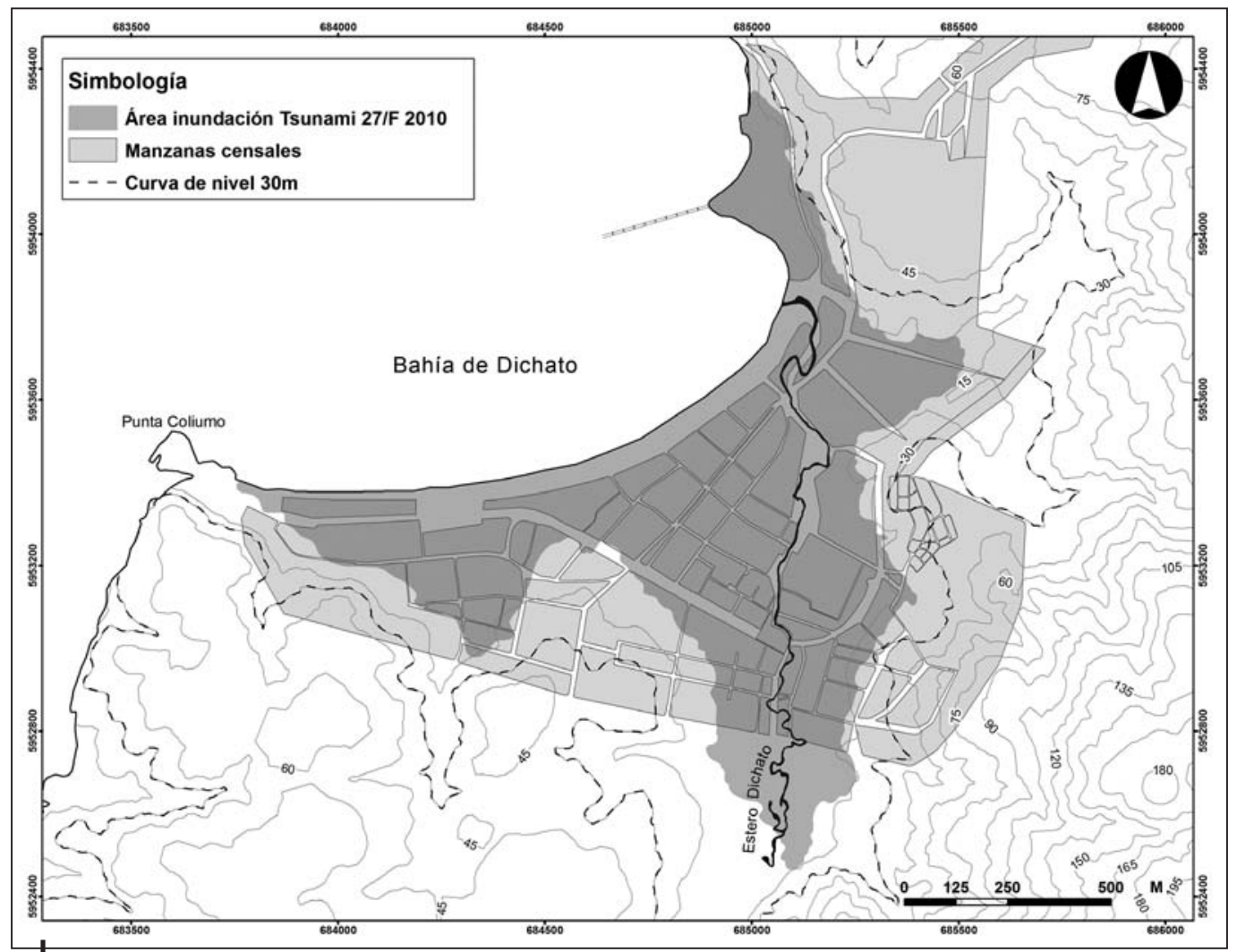

Figura 4 - Área de inundación por el tsunami del 27/F de 2010, localidad de Dichato Fuente: Elaboración propia

Se estableció que para condiciones posevento el 74\% de la población de Dichato, localizado bajo la cota de los 25 msnm, presentó vulnerabilidad total alta (fig. 5), involucrando el 94\% de la superficie total del área, 66\% de las manzanas censales y $69 \%$ de las viviendas. Una vez ocurrido el tsunami, es decir para condiciones posevento, se determinó que el $72 \%$ de las manzanas censales fueron afectadas por el tsunami, así también el 73\% de los habitantes y el 70\% de las viviendas.

\section{2. 2. Vegas de Coliumo}

Se determinó para Vegas de Coliumo que el 44\% de la población (190 habitantes) presenta una vulnerabilidad física alta y el 30\% de esta un nivel medio (Ireland, 2012), lo cual se explica por la localización de las viviendas en áreas propensas a tsunamis y por la baja materialidad de las viviendas, catalogadas de baja resistencia ante estos fenómenos. Desde el punto de vista socioeconómico se estableció que el $65 \%$ de la población (279 habitantes) presentó un nivel de vulnerabilidad alto 
Factores de vulnerabilidad y reconstrucción posterremoto en tres localidades costeras chilenas

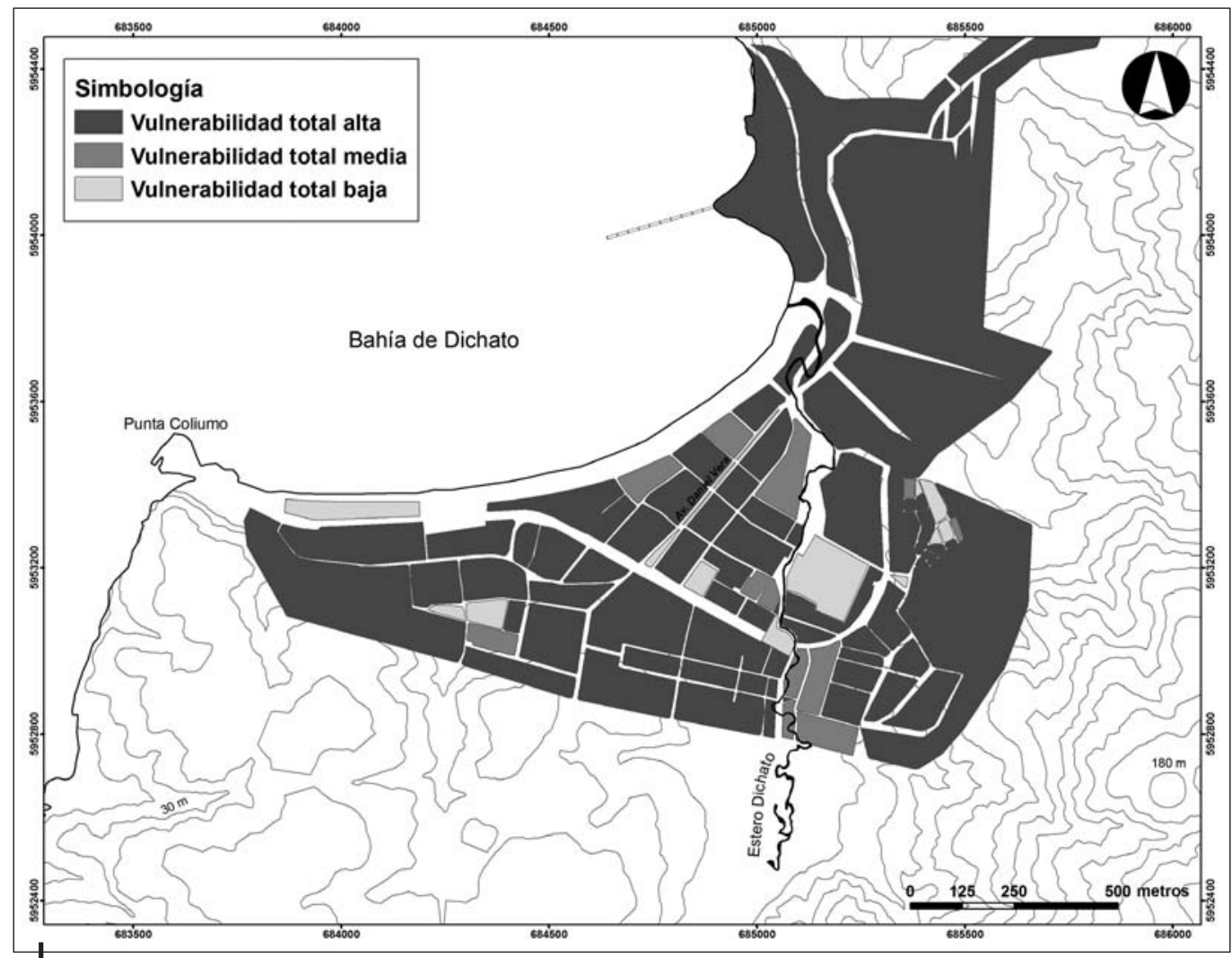

Figura 5 - Nivel de vulnerabilidad total por tsunami, localidad de Dichato Fuente: Modificado de Venegas (2012)

y el $28 \%$ un nivel medio. Esto último se asoció por un lado a la dependencia de la población en actividades primarias de pesca, agricultura y ganadería, las cuales vincularon al 85\% de la población. Por otro lado, el 70\% de la población se clasificó en el I y II quintil; es decir, los niveles de ingresos más bajos.

El sector de Vegas de Coliumo presentó características propias del medio rural. Además tiene una influencia pesquera, lo cual se reflejó en el tipo y calidad de la vivienda, pero sumado a una localización propensa los resultados fueron una alta vulnerabilidad física. En este marco, el sector presentó mayoritariamente bajos niveles de precariedad, dado que la mayoría de las viviendas está en la categoría de casas. Respecto a la calidad de las viviendas, estas fueron construidas principalmente de madera, material común en viviendas rurales; por lo tanto, son consideradas medianamente resistentes frente al riesgo de tsunami.

Desde el punto de vista ideológico-cultural, el 2,6\% de la población presentó una vulnerabilidad alta, mientras que el $60 \%$ un nivel medio. Esto debido a que se encontró un bajo nivel de adaptabilidad de la población ante un nuevo evento de 
tsunami ya que presentan un sentimiento de indiferencia ante la posibilidad. El nivel de conocimiento del evento es adecuado debido a que este ha sido transferido de generación en generación, por tratarse de una de las caletas pesqueras más antiguas de la región. De acuerdo con esto y considerando el comportamiento de las diferentes dimensiones de la vulnerabilidad, se estableció que el 35\% de la población presenta vulnerabilidad total alta y el 53\% media (fig. 6).

\section{2. 3. Tubul}

La vulnerabilidad física para la localidad presentó solo niveles altos (42\% de la población) y medios (58\% de la población). En todos estos casos, todas las viviendas se localizaron bajo la cota de los $10 \mathrm{msnm}$. La vulnerabilidad socioeconómica de la población de Tubul se determinó como alta para el 33\% de la población, donde primaron los bajos niveles de ingreso y altos niveles de pobreza asociada. La vulnerabilidad media afectó al $64 \%$ de la población. La vulnerabilidad educativa media se presentó en el 79\% de la población, con un nivel de escolaridad hasta enseñanza básica, mientras que la vulnerabilidad alta se estableció para el $21 \%$ de esta.

Los niveles de vulnerabilidad total de la localidad fueron medios y altos (Altamirano, 2012), explicados por la localización de las viviendas en cota de inundación, su materialidad (madera o lata), el nivel de ingreso, la escolaridad y la reacción frente al fenómeno (fig. 7).

En la localidad el grado de dependencia de actividades extractivas asociadas a la pesca es alto, vinculantes a nivel de grupo familiar. Los niveles de ingresos se situaron entre los dos primeros quintiles, por lo tanto son bajos. Cerca del 90\% de la población se catalogó como pobre, lo cual se agravó en condiciones posterremoto debido a la pérdida de la fuente laboral. Si bien la escolaridad es baja en la localidad (educación primaria incompleta), el nivel de conocimiento sobre las causas que generan un tsunami es bueno sobre el 40\% de la población, por lo cual la vulnerabilidad educativa resultó con un nivel medio.

\section{3. El proceso de reconstrucción y las nuevas áreas de riesgo}

La reconstrucción posterremoto de las ciudades y localidades costeras del país fue abordada por los gobiernos regionales de las regiones de Valparaíso, del Maule y del Biobío. En el caso de esta última, la Intendencia Regional a través de una Comisión Intersectorial de Reconstrucción diseñó el Plan de Reconstrucción del Borde Costero (PRBC-18) para las 18 localidades afectadas por el terremoto y tsunami del 27/F de 2010. Este plan ha sido ejecutado por el Ministerio de Vivienda y Urbanismo bajo el principio de orientar la reconstrucción hacia una restauración urbanística de calidad, inclusiva e integral, capaz de articular con los instrumentos de planificación territorial a nivel local. A través de fondos centralizados del gobierno se aplicó una política de subsidios para la reconstrucción compartida en el caso de sitios propios o pérdida parcial, o social en el caso de relocalizaciones 
Factores de vulnerabilidad y reconstrucción posterremoto en tres localidades costeras chilenas

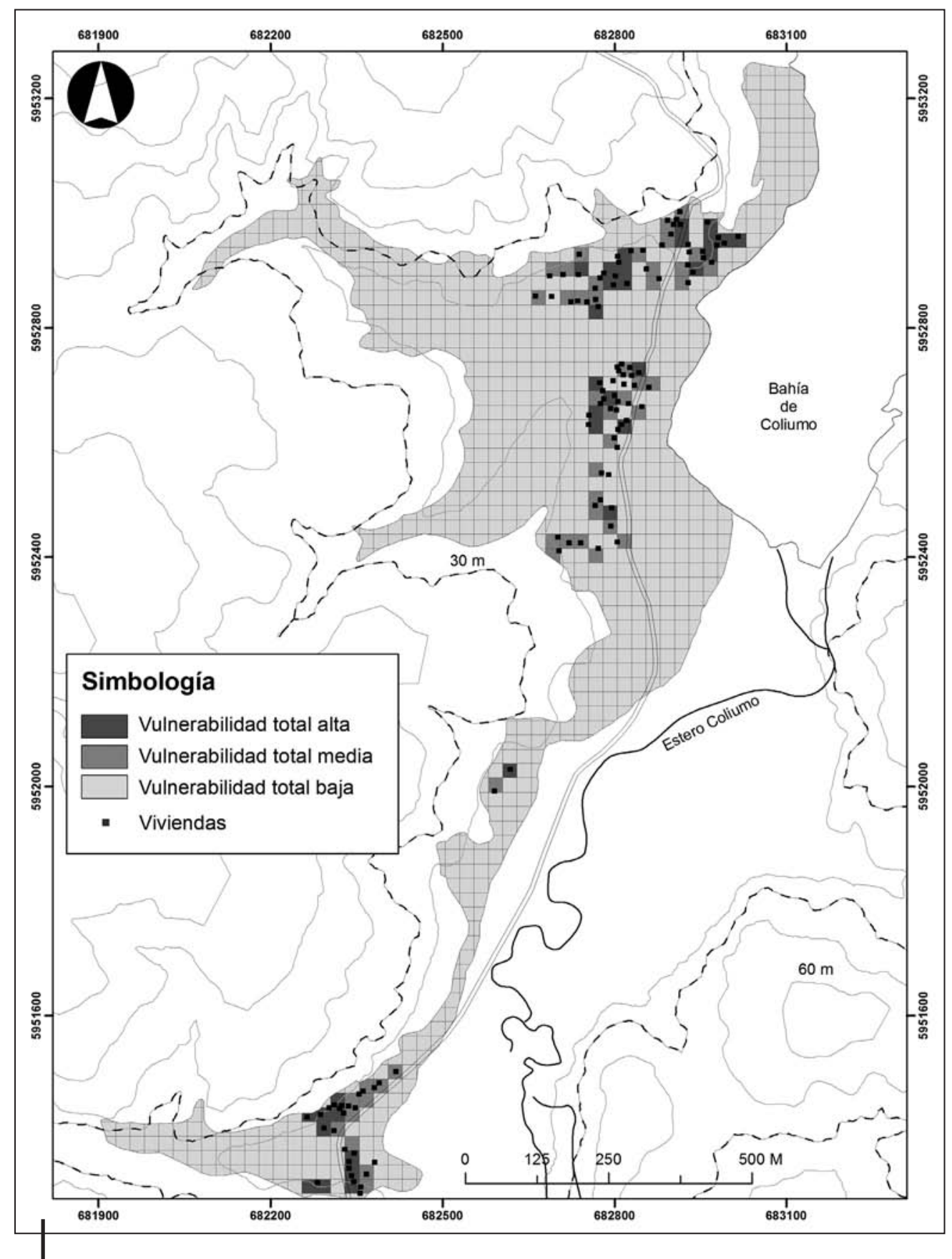

Figura 6 - Nivel de vulnerabilidad total por tsunami, localidad de Vegas de Coliumo Fuente: Modificado de Ireland (2012) 


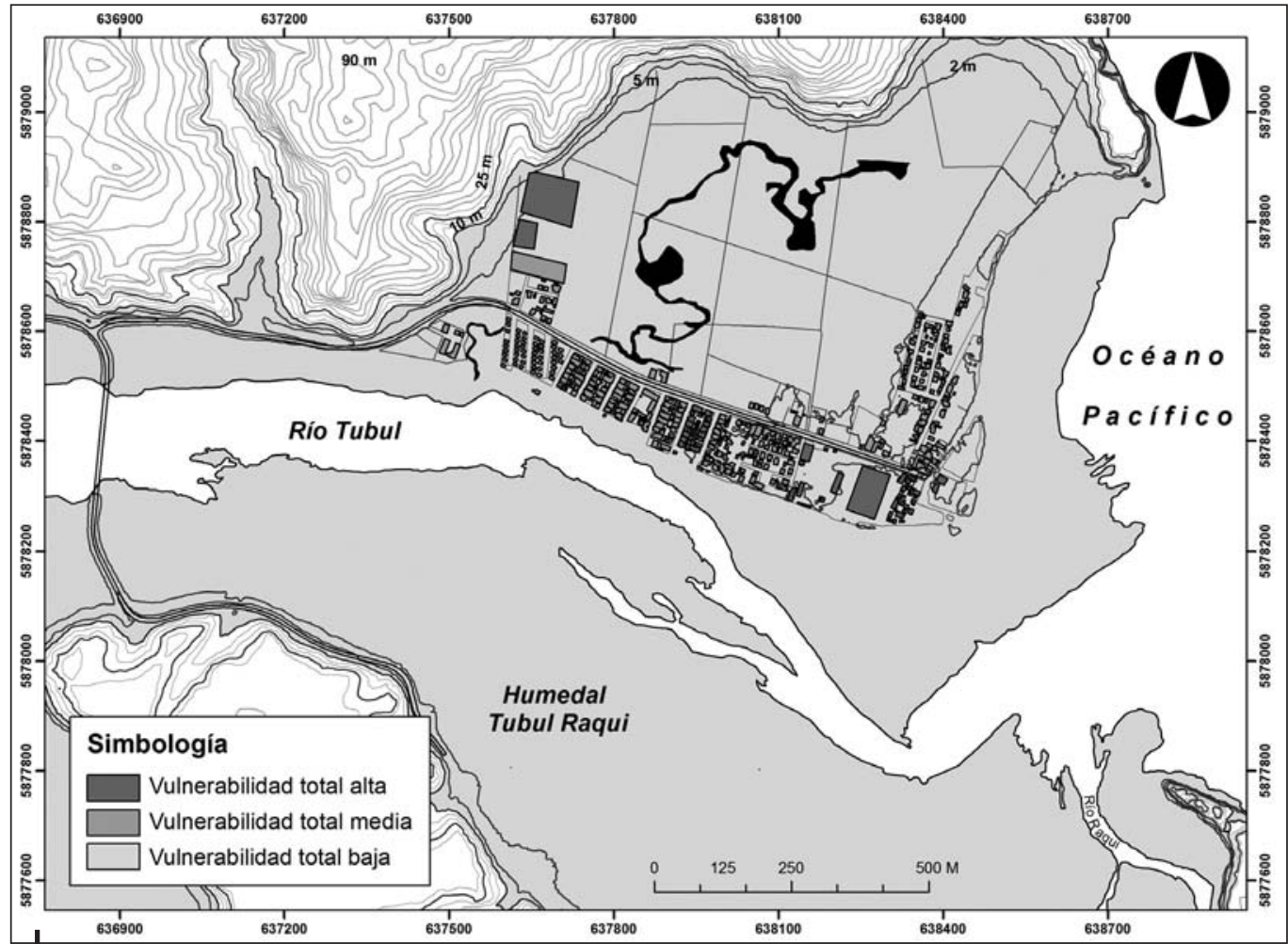

Figura 7 - Nivel de vulnerabilidad total por tsunami, localidad de Tubul Fuente: Martínez et al., (2012)

de construcción de viviendas sociales. Una prioridad fue la ejecución de proyectos de inversión para recuperación de infraestructura, principalmente conectividad y mitigación (muros de contención y parques de mitigación).

\section{3. 1. Dichato}

Actualmente la localidad de Dichato es el área con mayor transformación a cuatro años de ocurrido el terremoto del 27/F y donde se han emplazado las viviendas tsunami-resistentes y antitsunami, actualmente denominadas «viviendas del borde costero». Estas últimas están emplazadas en la zona más cercana a la orilla de playa y colindan con el parque de mitigación (arboleda) que se proyectó en la mayoría de las localidades costeras afectadas por el tsunami (fig. 8).

Las viviendas tsunami-resistentes observadas se caracterizan por una base de pilares de hormigón de $3 \mathrm{~m}$ de alto con unos $30 \mathrm{~m}^{2}$ de superficie construida en dos pisos (fig. 9A). Se han construido sobre los mismos terrenos de propietarios, de manera dispersa ya que muchos de los pobladores afectados son personas de la tercera edad que no están en condiciones de hacer uso de las escaleras debido a 
Factores de vulnerabilidad y reconstrucción posterremoto en tres localidades costeras chilenas

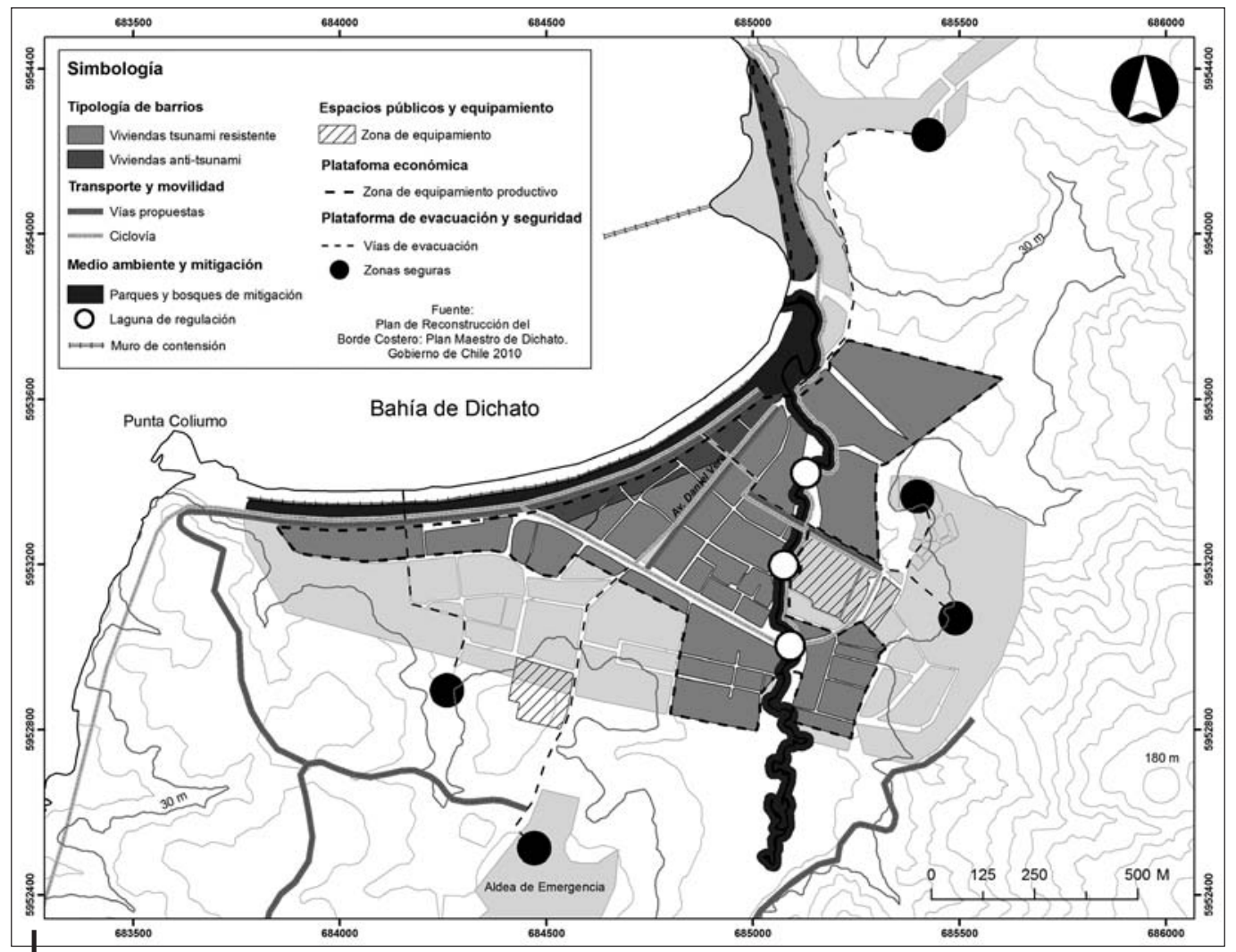

Figura 8 - Plan de Maestro de Reconstrucción posterremoto 27/F 2010, localidad de Dichato Fuente: Elaboración propia a partir de Plan Maestro de Reconstrucción

su gran altura, por lo cual optaron por erradicar a sectores de cerros donde se están construyendo las viviendas definitivas. Se ha observado además que el sistema de palafito está siendo utilizado para ampliar el primer piso de la vivienda y se ha cubierto con internit o madera en la mayoría de los casos; por lo tanto, su diseño y razón de ser no se ha asimilado o no es compartido por los habitantes (fig. 9B).

Una segunda versión de vivienda tipo palafito (anti-tsunami) se localiza en el sector de Villarrica de Dichato, donde se emplazaron unas 12 viviendas con pilares de base metálica y construcción en altura en dos pisos, se estimó una superficie de $40 \mathrm{~m}^{2}$ aproximadamente (fig. 10). Estas viviendas se localizan en la primera línea de edificación y son las más cercanas a la línea de playa.

El Plan de Reconstrucción de Dichato modificó el 29\% de la superficie total de la localidad, donde el 15\% se estableció como zona de edificación condicionada, sin incluir la expropiación. El 12\% del área total se destinó a parques de mitigación, construcciones a lo largo de la costanera y el borde del estero de Dichato, por donde se encauzó el tsunami y se generó la mayor destrucción. 

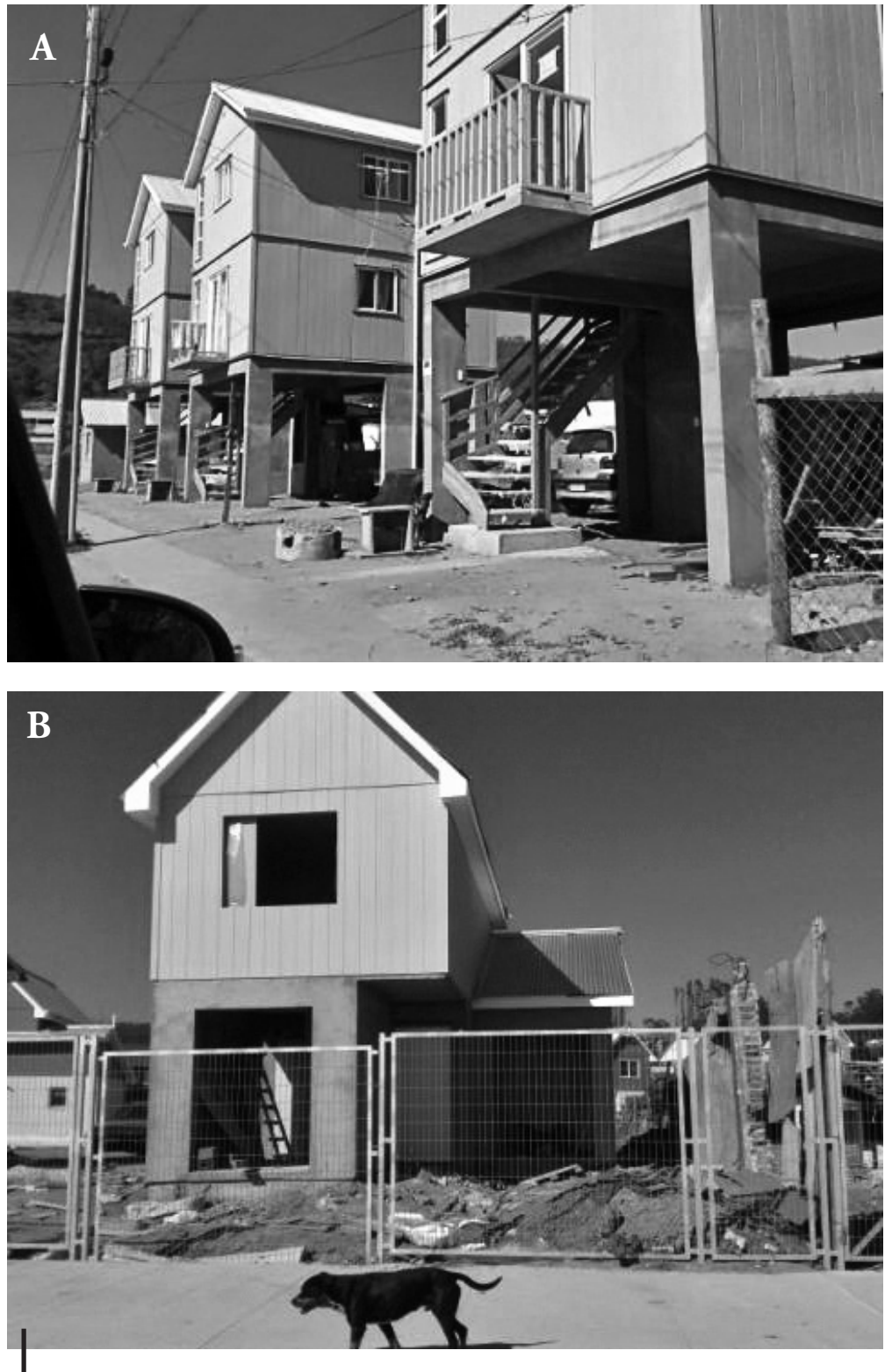

Figura 9 - Viviendas anti-tsunami localizadas en el borde costero de Dichato

A. Viviendas tipo palafito con pilares de hormigón, zona centro de Dichato;

B. Viviendas tipo palafito con pilares metálicos, sector Villarrica, Dichato 
Factores de vulnerabilidad y reconstrucción posterremoto en tres localidades costeras chilenas
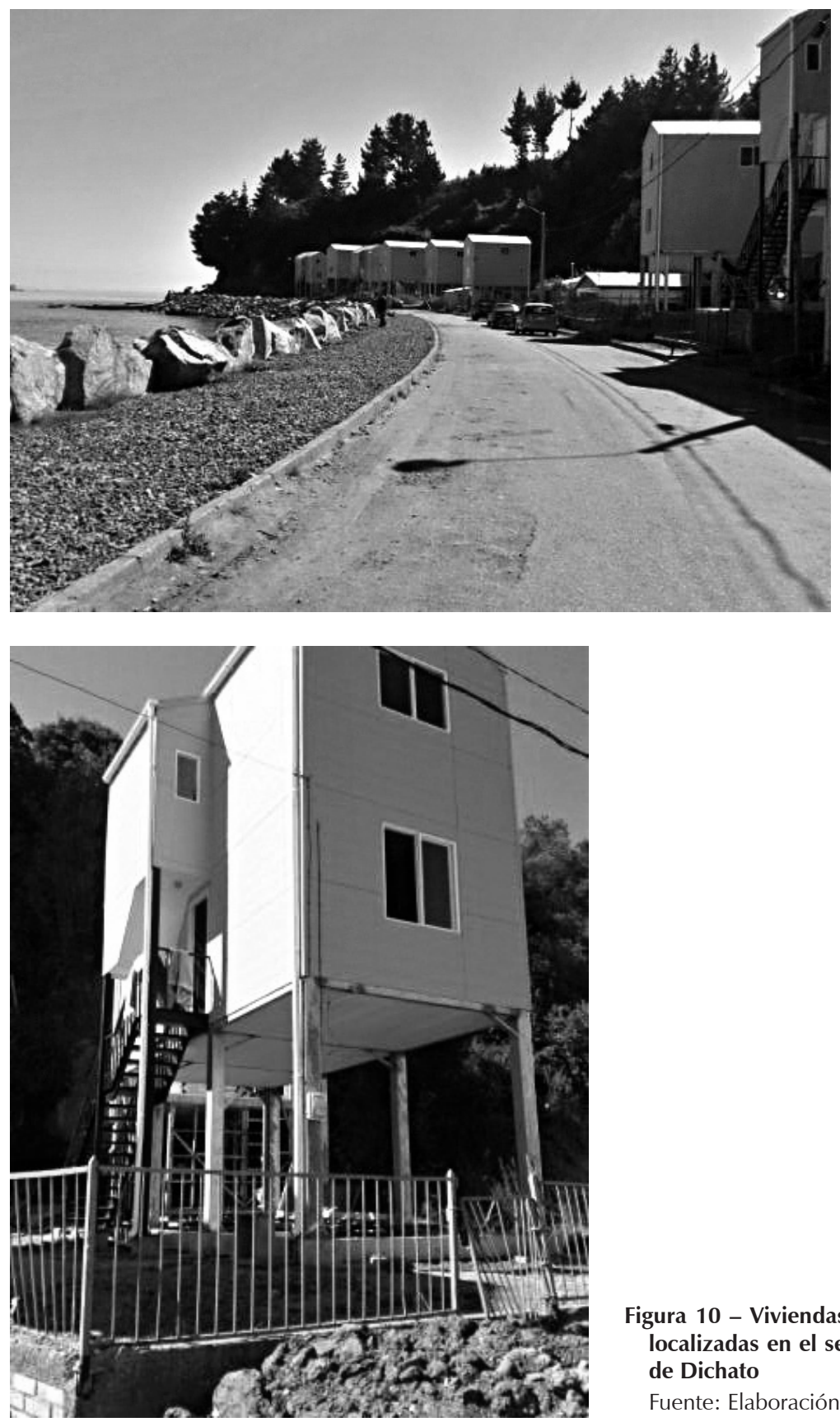

Figura 10 - Viviendas anti-tsunami localizadas en el sector Villarrica de Dichato

Fuente: Elaboración propia 
El $1,6 \%$ de la superficie total fue destinada a la actividad pesquera, con la construcción de un muelle pesquero y un mercado en el sector de la Caleta Villarrica. A la fecha, el parque de mitigación no se ha construido aquí ni en alguna de las localidades que cuentan con un Plan Maestro de Reconstrucción, mientras que las obras de encauzamiento del estero Dichato aún se están ejecutando.

En general, lo que aquí se observa es una mezcla de viviendas derivadas del proceso de reconstrucción y autoconstrucción en sitios propios, que generan dicotomías de barrios en torno a una identidad perdida y en proceso de lenta restauración.

Las viviendas sociales proyectadas y que ya han sido entregadas corresponden a soluciones habitacionales para aldeas que albergaron durante tres años a los damnificados del tsunami, principalmente la Aldea El Molino, ubicada en sectores más altos dentro de la cota segura. La nueva solución habitacional se emplazó frente a la aldea y ahí se han conformado unas 200 viviendas nuevas. Los otros sectores de relocalización tales como El Sauce, Villa Miramar, Ferrocarriles y Villarrica, que comprenden en total unas 330 viviendas, se localizan todas dentro de la cota de inundación por tsunami.

\section{3. 2. Vegas de Coliumo}

En la localidad de Vegas de Coliumo se identificaron unas 21viviendas tsunamiresistentes de tipo palafito, similares a las encontradas en Dichato, que fueron las proyectadas por el Plan de Reconstrucción de Coliumo (fig. 11) a lo largo del borde costero. Fueron construidas en terrenos propios, pero hoy presentan graves problemas de urbanización con filtrado de aguas servidas. Los antiguos propietarios indicaron en las encuestas realizadas que esas viviendas no podrían reemplazar a aquellas que tenían y que los vinculaba al medio; sin embargo, decían no entender la situación de insalubridad con la que actualmente deben convivir (figs. 12 y 13). El primer piso de la vivienda (sector palafito) es ocupado para guardar equipamiento pesquero o arreglar redes de pesca.

\section{3. 3. Tubul}

La localidad de Tubul actualmente experimenta un fuerte proceso de urbanización que de acuerdo al Plan Maestro de Reconstrucción (fig. 14) considera ocupar las mismas áreas de peligro que los tsunamis históricos han inundado. Se trata de una zona de humedal que contiene áreas frágiles y que hasta antes del tsunami del 27/F desarrollaba actividades extractivas estrechamente vinculadas a una organización social cohesionada en sindicatos de pescadores y recolectoras de algas, las cuales llevaban explotando el alga gracilaria («pelillo») desde los años setenta. El tsunami del 27/F desecó el humedal que ha venido recuperándose lentamente, sin embargo la población de algas aún no se ha recuperado. Actualmente los grupos de mujeres recolectoras organizadas se han reconvertido a diversos trabajos temporales, incluso se les ve como personal obrero en las obras de construcción de caminos y servicios básicos que se están ejecutando en el área. 
Factores de vulnerabilidad y reconstrucción posterremoto en tres localidades costeras chilenas

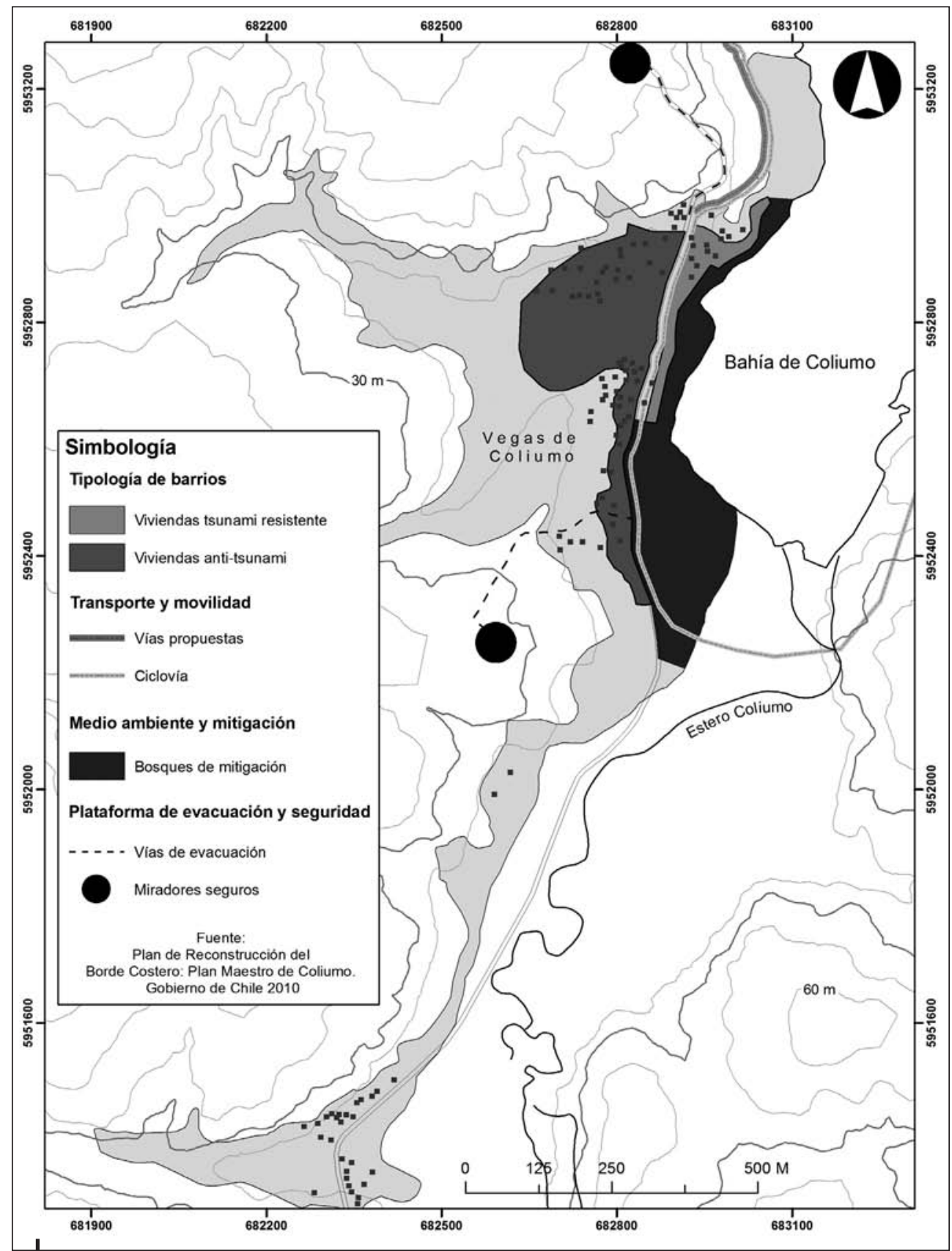

Figura 11 - Plan de Maestro de Reconstrucción posterremoto 27/F de 2010, localidad de Vegas de Coliumo

Fuente: Elaboración propia a partir de Plan Maestro de Reconstrucción 

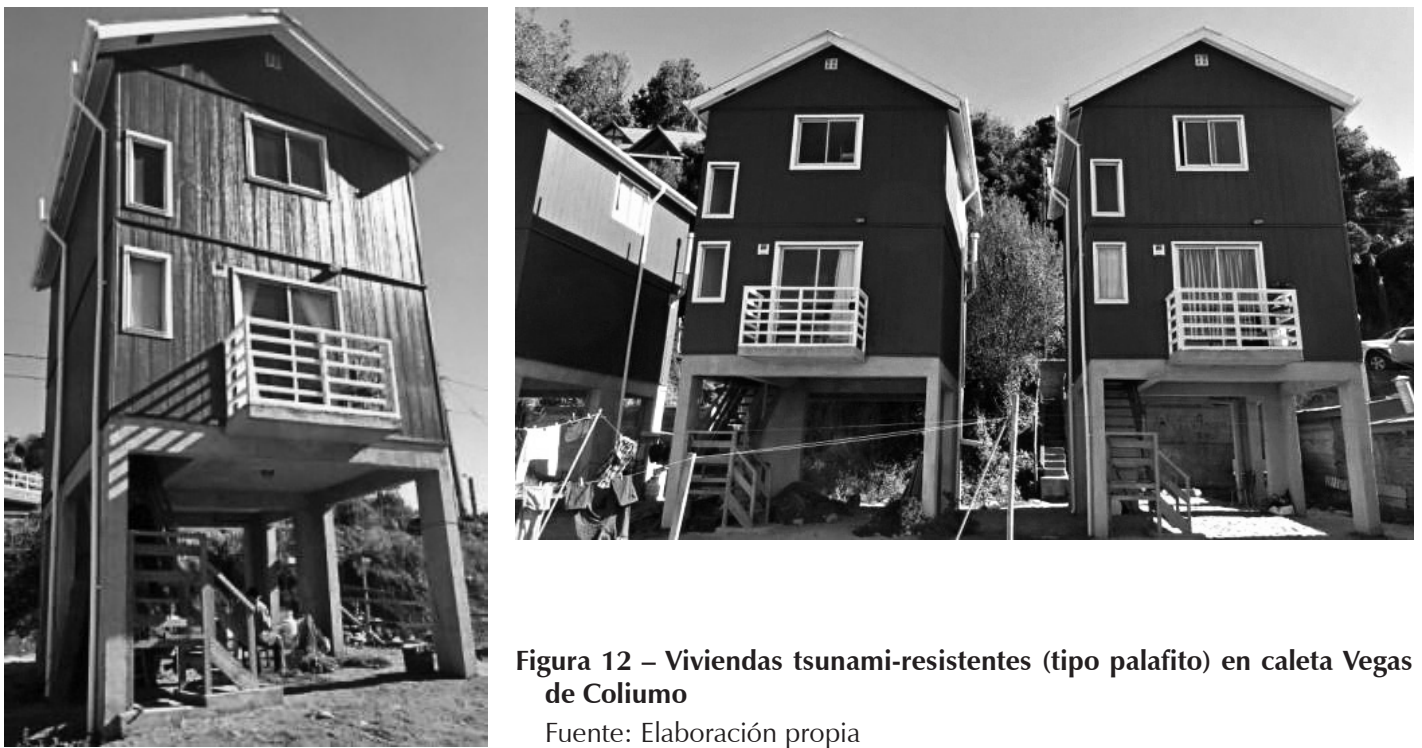

Figura 12 - Viviendas tsunami-resistentes (tipo palafito) en caleta Vegas de Coliumo

Fuente: Elaboración propia

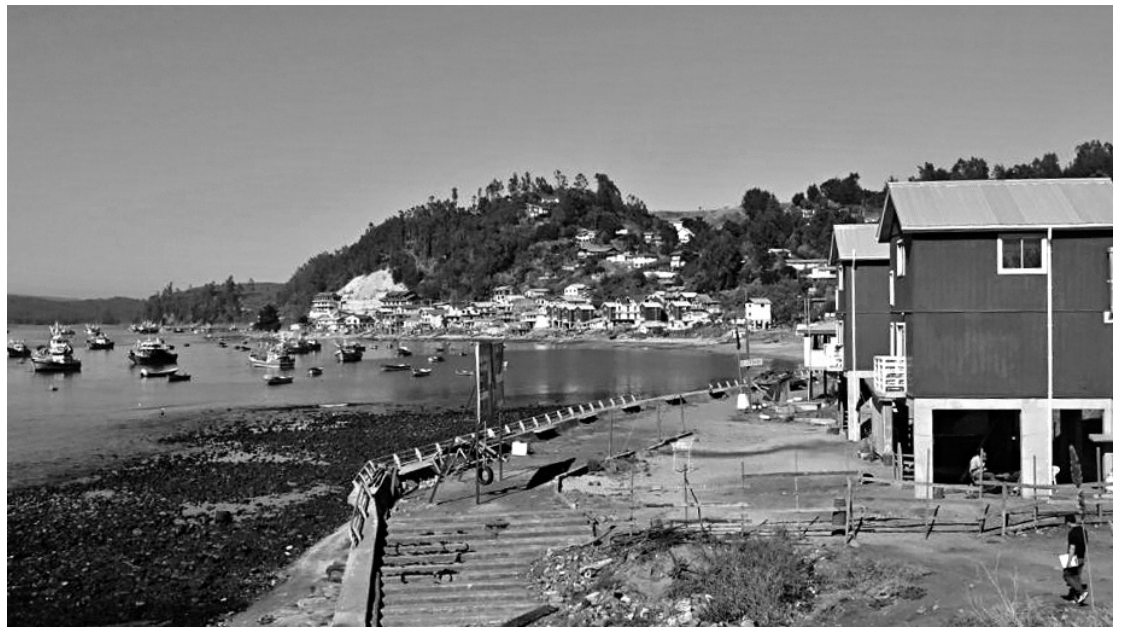

Figura13 - Vista general de viviendas tsunami-resistentes en caleta Vegas de Coliumo Fuente: Elaboración propia 


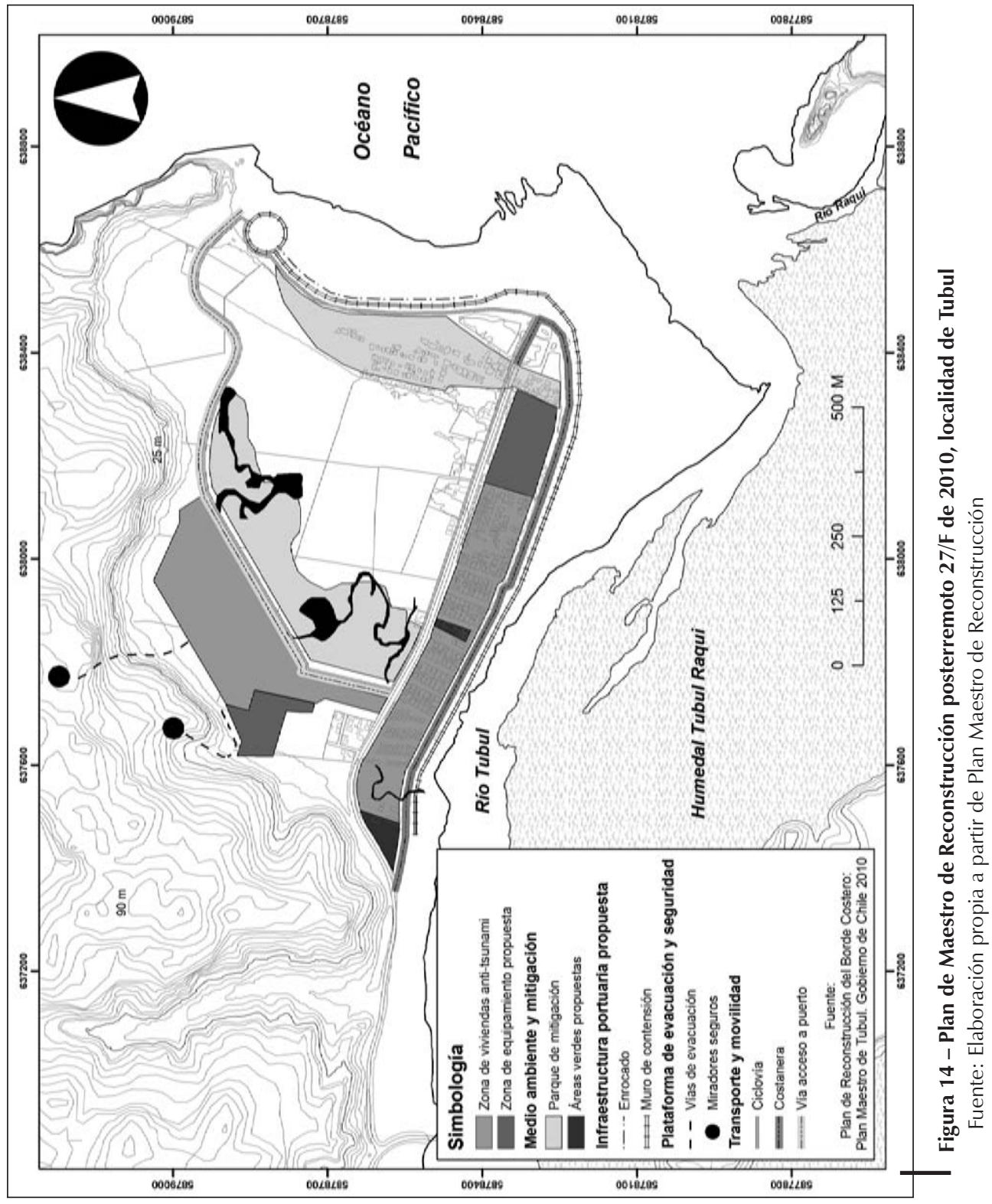


El tipo de vivienda que se está construyendo como parte de la reconstrucción en Tubul no se ha encontrado en otras localidades afectadas por el tsunami del $27 / F$, ya que se trata de unas 40 viviendas con base de hormigón, de $52 \mathrm{~m}^{2}$ de superficie construida y un segundo piso de madera; emplazamiento que contrasta con el tipo de vivienda de material ligero y de alta precariedad que imperaba en la caleta antes del tsunami (fig. 15). Sin embargo, esto ocurre solo en los sectores localizados en la ribera del río Tubul, en manzanas que antes ocupaban viviendas precarias y que hoy en día están consolidando el asentamiento en las áreas de peligrosidad más altas.

Otros proyectos de viviendas sociales de menor superficie y calidad se están construyendo en las áreas húmedas interiores, en zonas donde los niveles freáticos

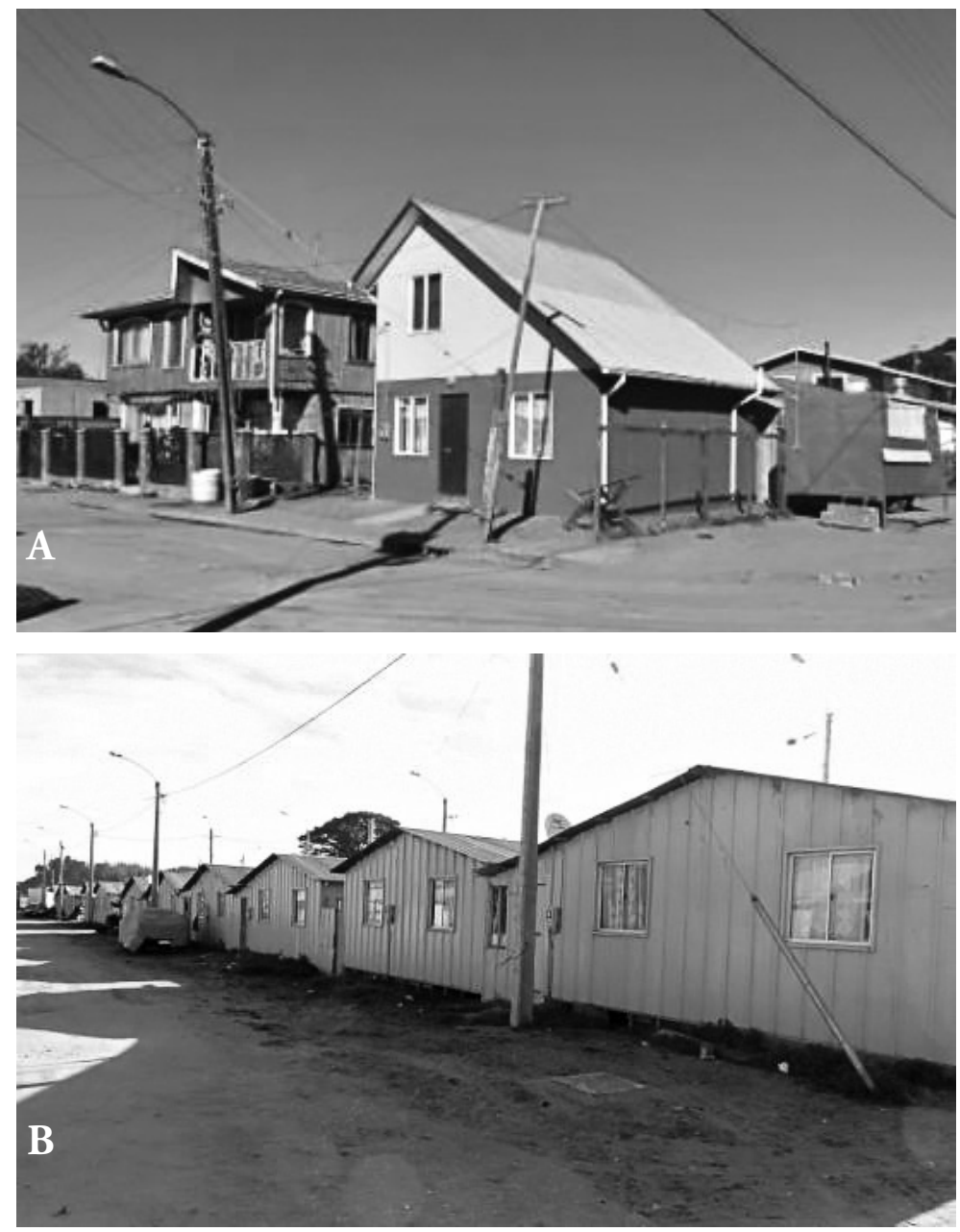

Figura 15 - Viviendas definitivas (A) y provisorias (B) en la localidad de Tubul Fuente: Elaboración propia 
ascienden instantáneamente durante la época de lluvias invernales. Dichas áreas, por ubicarse dentro de una antigua llanura fluviomarina con características estuariales, deberían ser tratadas a través de un plan de manejo. Estas viviendas ya forman grupos consolidados con vialidad asociada y representan soluciones habitacionales para familias afectadas de otras localidades. Se estima que unas 150 viviendas ya han sido emplazadas en estos sectores de áreas húmedas, localizadas en cotas inferiores a $10 \mathrm{~m}$. Estos nuevos emplazamientos de población relocalizada no se encuentran representados en el Plan Maestro al igual que la caleta de pescadores que actualmente se construye en la playa Tubul. Estas obras han destruido la fisonomía del estuario y generado continuos trabajos de dragado por la alteración en sus procesos sedimentarios.

La infraestructura que se construye contrasta con la realidad social y cultural de la localidad donde un proceso de urbanización intensiva se sobreimpone a un área rural que aún no se adapta a la nueva realidad geográfica posterremoto, donde los recursos naturales asociados al mar y al humedal hoy ya no están disponibles según la antigua organización social. A esto se agrega la intensa carga sobre estas escasas áreas húmedas con población que ha duplicado la que había antes del tsunami.

\section{CONCLUSIONES}

En Chile, efectivamente se está desarrollando un proceso de reconstrucción que, en términos de recuperación y mejoramiento de infraestructura posterremoto, se puede considerar exitoso. Sin embargo, la realidad que viven los asentamientos de pequeñas caletas y localidades costeras de la Región del Biobío no guarda relación con las propuestas centralizadas de los Planes Maestros de Reconstrucción (PRBC18), dado que no están pensados desde lo local y ni en relación con las características de los grupos humanos que habitan estos territorios transformados. Si bien estos Planes Maestros de Reconstrucción fueron proyectados con la finalidad de generar una reconstrucción correctiva, es decir con obras de mitigación ante la posibilidad de nuevos tsunamis, de calidad, inclusiva y con estándares de sustentabilidad urbana, reforzando la identidad local, esto no ha podido cumplirse debido a que se ha priorizado la reconstrucción física sobre lo social.

En varias de estas localidades se está elevando la vulnerabilidad ante tsunamis futuros y con ello creándose nuevos escenarios de riesgo debido a que no se conoce el tipo de sociedad que habita dicho territorio y sus relaciones vinculantes. Esto último es claro en Tubul donde investigaciones que han analizado el proceso de reconstrucción han establecido un aumento en la densificación de la población expuesta a nuevos eventos de tsunamis, una disminución del ingreso de los hogares especialmente en mujeres, aumento de inseguridad de la población (delincuencia) y disminución generalizada de la calidad de vida de la población (Martínez et al., 2012; Rojas et al., 2014). De ahí la importancia de estudios de vulnerabilidad y resiliencia social a nivel local y su inclusión en los instrumentos de planificación territorial. 
En Coliumo, por ejemplo, se observaron rasgos de topofilia muy marcados dado que la población local ha perdido el miedo ante estos fenómenos al arriesgar cotidianamente su vida en el mar y realizar sus actividades bajo un sentimiento de identidad con su entorno (la caleta) como reflejo de un modo de vida heredado ancestralmente (Ireland, 2012). Si se asume aquí una relación inversa con la resiliencia (Klein et al., 2003) la adaptabilidad es baja, por lo tanto las medidas que se deben adoptar para aumentar la resiliencia social deben ser no estructurales y orientadas fuertemente al trabajo de participación comunitaria, con el fin de aprovechar la alta cohesión social que presentan; situación que no se observó en Tubul o Dichato.

En Tubul, área rural, y al igual que Coliumo fuertemente dependiente de los recursos del mar, más que reconstruir estos vínculos se ha ido imponiendo un modelo de ciudad que no guarda relación con la identidad del lugar, con infraestructura que por otro lado destruye ambientes costeros frágiles, como son las marismas y áreas húmedas, hoy en día rellenadas para asentar las viviendas sociales.

En Dichato, localidad urbana, se está registrando por el contrario una pérdida de identidad como resultado del proceso de reconstrucción. Los nuevos barrios carecen de elementos armónicos y estructurantes priorizándose la solución habitacional con modelos traídos de otros contextos culturales (viviendas palafito). En este caso se impone una imagen de ciudad-balneario que genera dos áreas diferenciadas y contrastantes: la costanera-boulevard en el borde costero, destinado al equipamiento turístico y las viviendas del interior, irregulares en su fisonomía y funcionalidad, con población socialmente vulnerable y que aún no reconstruye su tejido interno.

Estas localidades tienen en común rápidas transformaciones territoriales que transitan más que a un control y manejo efectivo de las áreas de riesgo en la planificación, a la generación de nuevas realidades geográficas con elevadas vulnerabilidades socioterritoriales y nuevos riesgos asociados, debido a un manejo centralizado de las políticas públicas y sus instrumentos, donde se dificulta la inclusión social a un nivel local.

\section{Agradecimientos}

Este trabajo forma parte del Proyecto FONDECYT N 11100379 de CONICYT-Chile. Se agradece a los alumnos tesistas geógrafos María Fernanda Ireland, Jocelyn Venegas y Álvaro Altamirano por su participación y contribución en este proyecto.

\section{Referencias citadas}

ALTAMIRANO, A., 2012 - Análisis de vulnerabilidad por tsunami en la localidad de Tubul, Región del Bio Bío, Chile. Tesis para optar el título de Geógrafo; Universidad de Concepción (Inédito). 
BELMONTE-POOL, J., 1997 - Análisis del contacto sismogénico interplaca a lo largo de Chile, 148 pp. Tesis de Magíster en Ciencias (Inédito), Universidad de Chile, Departamento de Geofísica.

CARDONA, O., 2001 - Estimación Holística del Riesgo Sísmico utilizando Sistemas Dinámicos Complejos. Tesis Doctoral, Universitat Politècnica de Catalunya (versión electrónica).

CEPAL, 2007 - Información para la Gestión de Riesgos de Desastres. Estudios de Caso de Cinco Países, 54 pp.; Ciudad de México: Naciones Unidas, BID.

CISTERNAS, M., GOROGITÍA, N., TORREJON, F. \& URBINA, X., 2011 - Terremoto y tsunami de Chile central de 1730: ¿un gigante o una serie de eventos menores? XXXI Congreso Ciencias del Mar, 16-19 de agosto, Viña del Mar.

DÍAZ, J., 1992 - Estudio de fuentes de tsunamis y de terremotos: aplicación en el Norte de Chile y Sur de Perú. Memoria para optar el Título de Oceanógrafo; Universidad Católica de Valparaíso, Chile (Inédito).

FLORES, P., 2011 - Análisis de Vulnerabilidad por tsunami en la localidad de Arauco, Región del Bio-Bío, 157 pp. Tesis para optar al título de Geógrafo. Universidad de Concepción, Facultad de Arquitectura, Urbanismo y Geografía, Departamento de Geografía.

GÓMEZ OREA, D., 1998 - Evaluación de Impacto Ambiental, 260 pp.; Madrid: Agrícola Española.

INSTITUTO NACIONAL DE ESTADÍSTICAS (INE), 2003 - Censos de Población y Vivienda año 2002 según país, Región del Biobío. Santiago.

IRELAND, M., 2012 - Análisis de vulnerabilidad por tsunami en la localidad de Coliumo, Región del Biobío, 273 pp. Tesis para optar el título de Geógrafo; Universidad de Concepción, Facultad de Arquitectura, Urbanismo y Geografía, Departamento de Geografía.

KAUSEL, E., 1986 - Los terremotos de agosto de 1868 y mayo de 1877 que afectaron al sur de Perú y norte de Chile. Boletín de la Academia Chilena de Ciencias, vol. 3, n. ${ }^{\circ}$ : 8-13.

KLEIN, R., NICHOLLS, R. \& THOMALLA, F., 2003 - Resilience to natural hazards: How useful is this concept? Environmental Hazards, n. ${ }^{\circ}$ 5: 35-45.

LAGOS, M., 2000 - Tsunamis de origen cercano a las costas de Chile. Revista de Geografía Norte Grande, $\mathbf{n}^{\circ}$ 27: 93-102.

LAVELL, A., 2001 - Sobre la Gestión del Riesgo: apuntes hacia una definición. Disponible en http://www.bvsde.paho.org/bvsacd/cd29/riesgo-apuntes.pdf

LOMNITZ, C., 1970 - Major earthquakes and tsunamis in Chile during the period 1535 to 1955. Soderdruck aus der Geologischen Rundschau Band, vol. 59, n. 3: 938-690.

LOMNITZ, C., 1971 - Terremotos y Tsunamis en Chile. Revista Geofísica Panamericana, n. ${ }^{\circ}$ 1: 151-178.

LORCA, E. \& RECABARREN, M., 1994 - Terremotos y Tsunamis o Maremotos, 119 pp.; Santiago de Chile: Servicio Hidrográfico y Oceanográfico de la Armada de Chile, Comisión Oceanográfica Intergubernamental, Centro Internacional de Informaciones de Tsunami.

MARTÍNEZ, C., 2014 - Vulnerabilidades y desastres socio-naturales: aportes desde la Geografía al proceso de Reconstrucción en la Región del Biobío. Revista Geográfica del Sur, vol. 3, n. ${ }^{\circ}$ 2: 33-58.

MARTíNEZ, C., ROJAS, O., JAQUE, E., QUEZADA, J., VÁSQUEZ, D. \& BELMONTE, A., 2011 - Efectos territoriales del tsunami del 27 de febrero de 2010 en la costa de la 
Región del Biobío. Revista Geográfica de América Central, Número Especial EGAL, Costa Rica: 1-16.

MARTÍNEZ, C., ROJAS, O., ARÁNGUIZ, R., BELMONTE, A., QUEZADA, J., ALTAMIRANO, A. \& FLORES, P., 2012 - Riesgo de tsunami en Caleta Tubul, Región del Bio-Bío: escenarios extremos y transformaciones territoriales post-terremoto. Revista de Geografía Norte Grande, n. ${ }^{\circ}$ 53: 85-106.

MC-DONALD, J. \& SIMIONI, D., 1999 - Consensos urbanos: aportes del Plan de Acción Regional de América Latina y el Caribe sobre Asentamientos Humanos, 78 pp.; Santiago de Chile: Naciones Unidas, Comisión Económica para América Latina y el Caribe, División de Medio Ambiente y Asentamientos Humanos.

MINISTERIO DE PLANIFICACIÓN Y COOPERACIÓN (MIDEPLAN), 2007 - Serie análisis de resultados de la encuesta de caracterización socioeconómica nacional (Casen 2006). Santiago.

MINISTERIO DE VIVIENDA Y URBANISMO (MINVU), 2004 - El déficit habitacional en Chile. Medición de los requerimientos de vivienda y su distribución espacial, 102 pp.; Santiago de Chile: Ministerio de Vivienda y Urbanismo.

MONGE, J., 1993 - Estudios de riesgo de tsunami en costas chilenas. Jornadas Chilenas de Sismología e Ingeniería Antisísmica, n. ${ }^{\circ}$ 2: 3-22.

PALACIOS, A., 2012 - Sismicidad histórica de la ciudad de Concepción desde su fundación en 1550 hasta su traslado en 1751. Boletín. Servicio Nacional de Geología y Minería, n. ${ }^{\circ}$ 64: 3-41.

QUEZADA. J., JAQUE, E., BELMONTE, A., FERNÁNDEZ, A., VÁSQUEZ, D. \& MARTÍNEZ, C., 2010 - Movimientos cosísmicos verticales y cambios geomorfológicos generados durante el terremoto $\mathrm{Mw}=8,8 \mathrm{del} 27$ de febrero de 2010 en el centro-sur de Chile. Revista Geográfica del Sur, vol. 1, n. ${ }^{\circ}$ 2: 11-45.

ROJAS, O. \& MARTÍNEZ, C., 2011 - Riesgos Naturales: evolución y modelos conceptuales. Revista Universitaria de Geografía, vol. 20, n. ${ }^{\circ}$ 1: 83-116.

ROJAS, O., SÁEZ, K., MARTÍNEZ, C. \& JAQUE, E., 2014 - Efectos ambientales postcatástrofe en localidades costeras afectadas por tsunami en Chile: desde la emergencia a la Reconstrucción. Interciencia, 39 (en prensa).

ROMERO, H., FUENTES, C. \& SMITH, P., 2010 - Ecología política de los riesgos naturales y de la contaminación ambiental en Santiago de Chile: necesidad de justicia ambiental. Scripta Nova. Revista Electrónica de Ceografía y Ciencias Sociales, vol XIV, n. ${ }^{\circ} 331$ (52). Disponible en http://www.ub.es/geocrit/sn/sn-331/sn-33152.htm

URRUTIA, R. \& LANZA, C., 1993 - Catástrofes en Chile, 1541-1992, 440 pp.; Santiago de Chile: Editorial La Noria.

VARGAS, J., 2002 - Políticas públicas para la reducción de la vulnerabilidad frente a los desastres naturales y socio-naturales, 84 pp.; Santiago de Chile: Cepal.

VENEGAS, J., 2012 - Análisis de vulnerabilidad por tsunami en la localidad de Dichato, Región del Biobío, Chile, 210 pp. Tesis para optar el título de Geógrafo. Universidad de Concepción, Facultad de Arquitectura, Urbanismo y Geografía, Departamento de Geografía.

WILCHES-CHAUX, G., 1993 - La Vulnerabilidad Global. In: Los Desastres no son Naturales (A. Maskrey, ed.): 11-44; Bogotá: La Red, Tercer Mundo Editores. 